\title{
The role of polycarbonate monomer bisphenol-A in insulin resistance
}

\author{
Milos Pjanic ${ }^{\text {Corresp. } 1}$ \\ ${ }^{1}$ Department of Medicine, Division of Cardiovascular Medicine, Cardiovascular Institute, Stanford University School of Medicine, Stanford, California, \\ United States \\ Corresponding Author: Milos Pjanic \\ Email address: mpjanic@stanford.edu
}

Bisphenol A (BPA) is a synthetic unit of polycarbonate polymers and epoxy resins, the types of plastics that could be found in essentially every human population and incorporated into almost every aspect of the modern human society. BPA polymers appear in a wide range of products, from liquid storages (plastic bottles, can and glass linings, water pipes and tanks) and food storages (plastics wraps and containers), to medical and dental devices. BPA polymers could be hydrolyzed spontaneously or in a photo- or temperature- catalyzed process, providing widespread environmental distribution and chronic exposure to the BPA monomer in contemporary human populations. Bisphenol $A$ is also a xenoestrogen, an endocrine-disrupting chemical (EDC), that interferes with the endocrine system mimicking the effects of an estrogen and could potentially keep our endocrine system in a constant perturbation that parallels endocrine disruption arising during pregnancy, such as insulin resistance (IR). Gestational insulin resistance represents a natural biological phenomenon of higher insulin resistance in peripheral tissues of the pregnant females, when nutrients are increasingly being directed to the embryo instead of being stored in peripheral tissues. Gestational diabetes mellitus may appear in healthy non-diabetic females, due to gestational insulin resistance that leads to increased blood sugar levels and hyperinsulinemia (increased insulin production from the pancreatic beta cells). The hypothesis states that unnoticed and constant exposure to this environmental chemical might potentially lead to the formation of chronic low-level endocrine disruptive state that resembles gestational insulin resistance, which might contribute to the development of diabetes. The increasing body of evidence supports the major premises of this hypothesis, as exemplified by the numerous publications examining the association of BPA and insulin resistance, both epidemiological and mechanistic. However, to what extent BPA might contribute to the development of diabetes in the modern societies still remains unknown. In this review, I discuss the chemical properties of BPA and the sources of BPA contamination found in the environment and in human tissues. I provide an overview of 
mechanisms for the proposed role of bisphenol A in insulin resistance and diabetes, as well as other related diseases, such as cardiovascular diseases. I describe the transmission of BPA effects to the offspring and postulate that gender related differences might originate from differences in liver enzyme levels, such as UDP-glucuronosyltransferase, which is involved in BPA processing and its elimination from the organism. I discuss the molecular mechanisms of BPA action through nuclear and membrane-bound ER receptors, nonmonotonic dose response, epigenetic modifications of the DNA and propose that chronic exposure to weak binders, such as BPA, may mimic the effects of strong binders, such as estrogens. 


\section{The role of polycarbonate monomer bisphenol A in insulin resistance}

Milos Pjanic,

Department of Medicine, Division of Cardiovascular Medicine, Cardiovascular Institute, Stanford University School of Medicine, Stanford, California, United States

Address for correspondence:

Milos Pjanic

Department of Medicine, Division of Cardiovascular Medicine, Cardiovascular Institute, Stanford University School of Medicine, 300 Pasteur Drive

Stanford, CA $94305-5233$

Phone: (650) 498-4810

Email: mpjanic@stanford.edu

\section{Abstract}

Bisphenol A (BPA) is a synthetic unit of polycarbonate polymers and epoxy resins, the types of plastics that could be found in essentially every human population and incorporated into almost every aspect of the modern human society. BPA polymers appear in a wide range of products, from liquid storages (plastic bottles, can and glass linings, water pipes and tanks) and food storages (plastics wraps and containers), to medical and dental devices. BPA polymers could be hydrolyzed spontaneously or in a photo- or temperature- catalyzed process, providing widespread environmental distribution and chronic exposure to the BPA monomer in contemporary human populations.

Bisphenol $A$ is also a xenoestrogen, an endocrine-disrupting chemical (EDC), that interferes with the endocrine system mimicking the effects of an estrogen and could potentially keep our endocrine system in a constant perturbation that parallels endocrine disruption arising during pregnancy, such as insulin resistance (IR). Gestational insulin resistance represents a natural biological phenomenon of higher insulin resistance in peripheral tissues of the pregnant females, when nutrients are increasingly being directed to the embryo instead of being stored in peripheral tissues. Gestational diabetes mellitus may appear in healthy non-diabetic females, due to gestational insulin resistance that leads to increased blood sugar levels and hyperinsulinemia (increased insulin production from the pancreatic beta cells). The hypothesis states that unnoticed and constant exposure to this environmental chemical might potentially lead to the formation of chronic low-level endocrine disruptive state that resembles gestational insulin resistance, which might contribute to the development of diabetes. The increasing body of evidence supports the major premises of this hypothesis, as exemplified by the numerous publications examining the association of BPA and insulin resistance, both epidemiological and mechanistic. However, to what extent BPA might 
47 contribute to the development of diabetes in the modern societies still remains 48 unknown.

In this review, I discuss the chemical properties of BPA and the sources of BPA contamination found in the environment and in human tissues. I provide an overview of mechanisms for the proposed role of bisphenol $\mathrm{A}$ in insulin resistance and diabetes, as well as other related diseases, such as cardiovascular diseases. I describe the transmission of BPA effects to the offspring and postulate that gender related differences might originate from differences in liver enzyme levels, such as UDPglucuronosyltransferase, which is involved in BPA processing and its elimination from the organism. I discuss the molecular mechanisms of BPA action through nuclear and membrane-bound ER receptors, non-monotonic dose response, epigenetic modifications of the DNA and propose that chronic exposure to weak binders, such as BPA, may mimic the effects of strong binders, such as estrogens. 
63

64

65

66

67

68

69

70

71

72

73

74

75

76

77

78

79

80

81

82

83

84

85

86

87

88

89

90

91

92

93

94

95

96

97

98

99

100

101

102

103

104

105

106

107

108

\section{Introduction}

Bisphenol A (BPA, IUPAC ID: 4,4'-(propane-2,2-diyl)diphenol) is one of the most extensively used synthetic monomers that in a polymerized state constitutes polycarbonate plastics and epoxy resins and makes up the significant part of the plastic environment that surrounds modern human species. Bisphenol $A$ is also a molecule that behaves as an endocrine-disrupting chemical (EDC) that is mimicking the effects of an estrogen (i.e. a xenoestrogen molecule). BPA could interfere with the endocrine system and promote a chronic imbalance that parallels endocrine disruption that arises during pregnancy under the influence of estrogens, such as insulin resistance (IR).

Human populations are being continuously exposed to bisphenol $A$ to the extent that it could be considered a common environmental factor present since 1957, when the first production of BPA started. With over 6 billion pounds (2.7 million tonnes) of BPA produced in 2003 and incorporated into polycarbonate polymers, and estimated 4.5 million tonnes in 2015, BPA represents one of the most abundant chemicals that come in direct contact with human populations world-wide (Welshons et al., 2006). The volume of BPA production in the world is predicted to increase continuously, and it is presently estimated to surpass 5.4 million tonnes (Merchant Research \& Consulting Ltd, 2017). BPA is found in plastic bottles, plastic food containers, baby and water bottles, can and glass linings, various medical and dental devices, sealants for dental fillings, compact disks and electronics, eyeglass lenses, and even in the lining of water pipes and tanks (Talsness et al., 2009; Huang et al., 2012). BPA is the main monomer of epoxy resins which are being used as coating agents on the interior of many water storage tanks. Hence, BPA leaching from such widely used polymers may influence human health inadvertently through consuming water or food. In addition, canned food might represent one of the significant global sources of BPA, as it has been shown that the canned food is significantly more contaminated with BPA compared to the noncanned one and that the BPA levels from canned food did not differ between continents (Repossi et al., 2016). In addition to dietary ingestion, a significant source of BPA exposure in modern human populations represents thermal paper used for supermarket and ATM receipts, that could efficiently transfer BPA to skin when holding the source for as long as $5 \mathrm{~s}$, and it remains largely extractable after $2 \mathrm{~h}$, indicating perfusion into the skin to such depths that it could no longer be removed or washed off easily (Biedermann, Tschudin \& Grob, 2010; Ehrlich et al., 2014). Furthermore, one of the sources that could provide constant exposure to BPA is orthodontic material, as it has been shown that the eluents from orthodontic adhesives immersed in saline for 1 month at $37^{\circ} \mathrm{C}$ exhibit estrogenic action through the induction of MCF-7 cell proliferation, an estrogen-responsive cell line (Gioka et al., 2009).

In addition, BPA is found as an additive to various polyvinyl chloride (PVC) products, including food packaging stretch films (López-Cervantes \& Paseiro-Losada, 2003). Food and drink products are estimated to be the major source of BPA contamination, with detected concentrations reaching microgram $(\mu \mathrm{g})$ levels. BPA and several bisphenol A analogues, including bisphenol-F (BPF) and bisphenol-S (BPS), have been 
109 found in various categories of food and drink products including fruits, vegetables, dairy

110 products, cereals, beverages, fats and oils, fish and seafood, meat and meat products

111 and "other products" category using high-performance liquid chromatography-tandem

112 mass spectrometry (HPLC-MS/MS) (Liao \& Kannan, 2013). BPA was detected in 75\%

113 of the tested samples, and the detected concentration was ranging from the very limit of

114 quantification (LOQ) to $1.13 \mu \mathrm{g} / \mathrm{g}$ weight (mean value, $4.38 \mathrm{ng} / \mathrm{g}$ ). BPA and its

115 analogues have been shown to appear in the indoor dust, and dust ingestion may be

116 another significant source of contamination with BPA (Liao et al., 2012). The potential to

117 use BPA analogues, BPS and BPF, as substitutes in the production of plastics has been

118 debated, as BPA analogues have shown similar effects to BPA on the cellular level

119 (Verbanck et al., 2017).

120

121

122

The global industrial trend of polycarbonate consumption is increasing from 1.6 million tonnes in 2000 up to 3.4 million tonnes in 2010 , and 4.5 million tonnes estimated in (predominantly China), that accounted for $59 \%$ of the polycarbonate consumption in 2010 and $68 \%$ estimated in 2015 . On the other side, Europe contributed with $32 \%$ of polycarbonate consumption in $2000,30 \%$ in 2010 , and estimated $25 \%$ in 2015 . Similar decreasing trend was observed for the United States $(28 \%$ in $2000,22 \%$ in 2010 , and $18 \%$ in 2015). Particularly, the production of BPA in China has grown extensively and this continuous trend will lead to the increasing BPA contamination in the global environment (Huang et al., 2012). The Environmental Protection Agency (EPA) in the US has established the tolerable daily intake (TDI) for BPA at $50 \mu \mathrm{g}$ per kg (body weight) per day in 1988 (Rubin, 2011). In January 2015, European Food Safety Authority has reduced TDI for BPA from 50 to $4 \mu \mathrm{g}$ per $\mathrm{kg}$ (body weight) per day. In addition, EPA has established the oral reference dose (RfD) for BPA at $100 \mu \mathrm{g} / \mathrm{L}$ as a standard for the total allowable concentration (TAC) in drinking water. Whether the extent of such exposure is significant has been debated (Nohynek et al., 2013), and various evidence have been presented supporting that the tight regulation of BPA is necessary. This is especially important considering the new knowledge about BPA action, including the numerous instances of experimental non-monotonic dose response to the BPA treatment, indicating narrow effective range of concentrations and the absence of effects on higher doses.

In this review, I present a global overview of the chemical properties of BPA and its polymers, their hydrolytic reaction and leaching BPA concentrations present in the environment and the corresponding concentrations in human tissues. Next, I define the physiological gestational insulin resistance (GIR), its pathophysiological progression to gestational diabetes and the role of estrogens in promoting these disorders. I elaborate on the proposed mechanism of BPA endocrine disruption, including non-monotonic dose response, and its transgenerational effects on male and female offspring, including epigenetic modifications transmitted to the next generation. Finally, I review the literature on biological effects of BPA in mice and humans including insulin resistance and diabetes, as well as in cardiovascular diseases such as coronary artery disease and other physiological disorders that BPA might contribute to. 
155

156

157

158

159

160

161

162

163

164

165

166

167

168

169

170

171

172

173

174

175

176

177

178

179

180

181

182

183

184

185

186

187

188

189

190

191

192

193

194

195

196

197

198

199

200

\section{Survey Methodology}

In order to survey the effects of BPA on insulin resistance I searched for studies analyzing BPA and insulin resistance on Pubmed or Pubmed Central (PMC) from their inception through May 2, 2017 using the following search algorithm: (bpa[Title/Abstract] OR bisphenol-A[Title/Abstract]) AND ("insulin resistance"[MeSH Terms] OR ("insulin"[Title/Abstract] AND "resistance"[Title/Abstract]) OR "insulin resistance"[Title/Abstract]). This search yielded the list of 19 publications on Pubmed Central and 86 publications on Pubmed. The survey of papers describing the influence of BPA on cardiovascular diseases was performed by applying the search algorithm: (bpa[Title/Abstract] OR bisphenol-A[Title/Abstract]) AND "cardiovascular disease*"[Title/Abstract], which yielded 33 publications on Pubmed and no publications on PMC. The search with algorithm: (bpa[Title/Abstract] OR bisphenol-A[Title/Abstract]) AND "cardiovascular"[Title/Abstract] yielded 97 publications on Pubmed and 5 publications on PMC. The survey of papers describing chemical properties of BPA molecule was performed with the algorithm: (bpa[Title/Abstract] OR bisphenolA[Title/Abstract]) AND "chemical properties"[Title/Abstract], which yielded 27 publications on Pubmed and no items on PMC. The survey of BPA concentration levels in both environment and human tissues was performed with the algorithm: (bpa[Title/Abstract] OR bisphenol-A[Title/Abstract]) AND "concentration*"[Title], yielding 89 publications on Pubmed and 12 on PMC. Papers with subject relevant to the search term and not present in the initial search were obtained through Similar Article Pubmed function. Initial papers that describe the structural and functional properties of BPA as an estrogen-like molecule from 1936 and 1938 were not present in the Pubmed or PMC databases and were found on Wikipedia and obtained from the JStore database. In addition, the search was performed using '*' symbol that denotes the truncated search terms to increase the number of publications obtained. After reviewing, articles were excluded from the study in case they were published in languages other than English or if they described subjects that were not related to the main search topic. Papers that did not contributed to the scientific understanding of the search topic were excluded, as well as papers that were addressing the same or similar subjects in order to eliminate the redundant studies. After filtering for each search term the number of papers retained were: BPA chemical properties - 6, BPA and insulin resistance relationship - 11, BPA and cardiovascular and other diseases - 4, and BPA and environmental and human tissue concentrations - 18. Additional papers were introduced after the revision process.

\section{BPA chemical properties, polymerization and hydrolysis.}

Bisphenol A (BPA), is an organic synthetic molecule composed of the two hydroxyphenyl groups connected through a carbon atom and, therefore, belonging to the group of diphenylmethane derivatives, with the formula $\left(\mathrm{CH}_{3}\right)_{2} \mathrm{C}\left(\mathrm{C}_{6} \mathrm{H}_{4} \mathrm{OH}\right)_{2}$. BPA holds certain steric resemblance to the estrogen molecule $17 \beta$-estradiol (E2), especially in the span of outer hydroxyl groups, and although it does not have the structure of a complete steroid ring, its behavior as a synthetic estrogen is based on the similar chemical 
201 properties, steric mimicking of an estrogen ring and on a weak interaction with the 202 estrogen receptors. BPA has an average mass of 228.3 Da, while estrogen E2 has an 203 average mass 272.4 Da (Pence \& Williams, 2010). BPA possesses experimental 204 melting point of $153-158{ }^{\circ} \mathrm{C}$ (Alfa Aesar), while E2 has a similar, but higher value 175$205178{ }^{\circ} \mathrm{C}$ (Alfa Aesar). Acidic dissociation constant, $\mathrm{K}_{\mathrm{a}}$, for BPA is 10.29 and for E2 is 10.27 (Bento et al., 2014). BPA cross-linking properties have propelled its utilization in the manufacturing of polycarbonate plastics and epoxy resins. The polymer structural properties and efficiency of polymerization and degradation when exposed to higher than normal temperatures are essential for the degree of contamination in the environment. The glass-liquid transition temperature ( $\mathrm{Tg}$, in amorphous materials represents transition from a compact glassy state into a viscous state) of BPA polycarbonate polymers is $147^{\circ} \mathrm{C}$, while heat deflection temperature (defining polymer deformation under a specified load) is $128^{\circ} \mathrm{C}$ under $1.8 \mathrm{MPa}$. Direct photochemical effect on BPA involves irreversible photo-scission leading to bisphenol-like products (Rivaton, Sallet \& Lemaire, 1983; Collin et al., 2012) and only secondary photoreactions are influenced by oxygen and may involve Photo-Fries rearrangement of the benzyl groups. On the other side, photo aging of the BPA polycarbonate has been shown also to occur through ring oxidation, e.g. resin was photo-oxidized under both sunlight $(A>300 \mathrm{~nm})$ and $\mathrm{Hg}$ arc light $(A>280 \mathrm{~nm})$ which indicated the loss of aromatic groups (Clark \& Munro, 1984). Capillary gas chromatogram showed BPA to be highly prevalent in the photo-aged polycarbonate product mixture (Factor, Ligon \& May, 1987). BPA, therefore has the potential of leaching out from the food and liquid storage units, as well as from the medical and dental materials, especially if exposed to higher temperatures or through a photo-oxidation mechanism.

\section{BPA exposure levels in human tissues}

In the late 90s Japan can industry has changed its formula for plastic can linings, which has been associated to over $50 \%$ decrease in human BPA levels and to the loss of correlation between usage of canned drinks and urine BPA levels in Japan (Matsumoto et al., 2003). A wider range of BPA levels has been detected in the adult and fetal serum in humans. Only two studies did not detect any BPA in humans, while in all other studies serum BPA was detected with the concentrations ranging from 0.32 to $4.4 \mathrm{ng}$ $\mathrm{ml}^{-1}$ (Vandenberg et al., 2007). Several studies testing various human tissues detected even higher BPA concentrations than those present in the serum, with the highest appearing in placenta $11.2 \mathrm{ng} \mathrm{ml}^{-1}$ (Schönfelder et al., 2002), umbilical cord $4.4 \mathrm{ng} \mathrm{ml}^{-1}$ (Todaka \& Mori, 2002), and amniotic fluid $8.3 \mathrm{ng} \mathrm{ml}^{-1}$ (Ikezuki et al., 2002), as well as in colostrum (late pregnancy milk) $3.4 \mathrm{ng} \mathrm{ml}^{-1}$ (Kuruto-Niwa et al., 2007) and breast milk $7.3 \mathrm{ng} \mathrm{ml}^{-1}$ (Ye et al., 2006). These independent findings are the indication of potential transmission of the effects of elevated BPA exposure from mothers to the progeny, either through placental transfer or breast feeding. The highest concentrations of BPA were found in human saliva immediately after the dental sealant application, $42.8 \mathrm{ng} \mathrm{ml}^{-}$ ${ }^{1}$, with the levels dropping to $7.9 \mathrm{ng} \mathrm{ml}^{-1} 1 \mathrm{~h}$ after the application (Joskow et al., 2006; Vandenberg et al., 2007). Recent study found significant differences in BPA concentrations in saliva between a group of patients with tooth surfaces filled with a 
247 polymer-based dental material and a control group without any polymer-based materials

248 ( $p=0.044$, Mann-Whitney $U$ test) (Berge et al., 2017). These findings imply a potential

249 long term exposure of BPA after dental surgeries.

250

251

252

253

254

255

256

257

258

259

260

261

262

263

264

265

266

267

268

269

270

271

272

273

274

275

276

277

278

279

280

281

282

283

284

285

286

287

288

289

290

291

292

In the human urine, BPA was found with detection rates from 52-100\% (Vandenberg et al., 2007). In the studies from 2005 to 2007, BPA was found in human urine with detection rates of $96 \%$ (Calafat et al., 2005), 89\% (Liu, Wolff \& Moline, 2005), 97\% (Ye et al., 2005), 97.5\% (Yang et al., 2006) and 94\% (Wolff et al., 2007). These results indicate that BPA in human urine has been almost completely detectable in all tested individuals and confirms broad human exposure to BPA. Another source of newborn and infant exposure to BPA might be the persistent leaching from the baby bottles. While a study from 1997 failed to detect any traces of BPA in baby bottles (Mountfort et al., 1997), a study from 2001 found $2.1 \mathrm{ng} \mathrm{ml}^{-1}$ in distilled water that came in contact with the baby bottles for $30 \mathrm{~s}$ at $100{ }^{\circ} \mathrm{C}$ (D'Antuono et al., 2001). Similarly, a study from 2003 found BPA leaching from the baby bottles in concentration of $0.23 \mathrm{ng} \mathrm{ml}^{-1}$ in the distilled water after $1 \mathrm{~h}$ at $100^{\circ} \mathrm{C}$, as well as increased BPA levels, ranging from 6.7 to $8.4 \mathrm{ng} \mathrm{ml}^{-1}$, after repeated cycles of bottle washing and brushing (Brede et al., 2003).

A study from 2004, found BPA leaching levels from a polycarbonate tubing to be as high as $3 \mathrm{ng} \mathrm{ml}^{-1}$ per day released into the passing water (Sajiki \& Yonekubo, 2004). More recent study found that BPA was detected in $46.9 \%$ of cardboard samples for the takeout food that could potentially be leaching the chemical to the packaged food (LopezEspinosa et al., 2007). These results indicate that water and food may be the dominant sources of BPA contamination depending on the composition of material used for their packaging and transport.

\section{Gestational insulin resistance and diabetes mellitus}

Gestational insulin resistance (IR) is a naturally occurring physiological phenomenon that arises during pregnancy in order to direct the blood circulating nutrients of pregnant females to the growing fetus (Mack \& Tomich, 2017). Gestational IR appears as the result of diabetogenic hormonal action originating from placenta, including hormones such as growth hormone, corticotropin-releasing hormone, placental lactogen and progesterone. Subsequently, as a response to increasing insulin resistance in the peripheral tissues, beta-cells of pancreas undergo hypertrophy and start secreting larger amounts of insulin. In certain cases, the inefficacy of larger levels of insulin to compensate for insulin resistance leads to gestational diabetes mellitus (GDM) that manifests as increased blood glucose levels in otherwise healthy pregnant females that had not been suffering from diabetes previously (Chiefari et al., 2017).

Long term consequences of gestational diabetes mellitus exist for both mothers and offspring. Even though in most cases the maternal blood glucose levels after pregnancy are brought down to normal levels, women that experiences GDM have higher risk for developing diabetes later in life (Damm et al., 2016). In fact, GDM is one of the strongest predictors of diabetes mellitus. It has been estimated that approximately one 
293 third of women that suffer from diabetes mellitus had experienced GDM previously

294 (Cheung \& Byth, 2003). Epidemiological studies indicate that the risk of developing type

2952 diabetes after suffering from GDM can be largely attenuated by lifestyle intervention

296 and physical activity by 50\% (Buchanan et al., 2002; Ratner et al., 2008). Long term

297 effects on the offspring of mothers with GDM have been less extensively studied,

298 however, in animal studies it has been shown that offspring of mothers with GDM have

299 increased risk of GDM, diabetes, obesity, cardiovascular disease and dysplasia of the

300 ventromedial hypothalamic nucleus, which is involved in the regulation of metabolism

301 and inhibits insulin secretion (Harder et al., 2001; Aerts \& Van Assche, 2006). In fact,

302 induced lesions in hypothalamic ventromedial nucleus in rats resulted in significant

303 hyperinsulinemia and increased blood glucose levels (Satoh et al., 1997). Therefore,

304 malformation of the ventromedial nucleus may be in part responsible for the persisting

305 alterations of glucose homeostasis found in the offspring of mothers with GDM.

306

307

GDM is one of the most dominant pregnancy complications as it affects from $2 \%$ to $10 \%$ of all pregnancies (Wedekind \& Belkacemi, 2016). During pregnancy, peripheral insulin resistance first appears as a physiological response to changes in steroid balance in the organism (Vejrazkova et al., 2014). In fact, the similar effect could be observed with the application of hormonal contraceptives, primarily those containing estrogens, that have been associated with changes in carbohydrate metabolism and increased insulin resistance (Lopez, Grimes \& Schulz, 2012). For example, one study showed 43-61\% increase in plasma glucose levels on the oral glucose-tolerance test (OGTT) in women taking oral contraceptives (Godsland et al., 1990), while other studies, in addition to increased OGTT plasma glucose, have found elevated fasting and post-glucose insulin levels and recommended that estrogen content of oral contraceptives should be reduced to minimize the diabetogenic effects (Wynn et al., 1979).

319

320

321

322

323

324

325

326

327

328

329

330

331

332

333

334

335

336

337

338

\section{BPA-induced endocrine disruption and insulin resistance}

In a 2014 study, it has been demonstrated that the offspring from BPA-exposed mice showed adverse symptoms of diabetes (García-Arevalo et al., 2014). In male offspring, the BPA treated group, similar to the groups fed with high fat diet (HFD) and with high fat diet plus BPA, showed fasting hyperglycemia, glucose intolerance and higher levels of insulin and free fatty acids. In 17-week old male offspring, under the fasting conditions, the BPA group of mice was hyperglycemic compared to the control, however this effect of BPA was masked under the high fat diet (HFD vs HFD-BPA). In addition, at 17 weeks, the BPA, HFD and HFD-BPA groups showed higher insulin levels than the control group. Intraperitoneal glucose tolerance test (ipGTT) showed higher glucose intolerance in the HFD and HFD-BPA groups compared to the control, while the BPA group showed a similar tendency without reaching the statistical significance. In 28week old male offspring, the BPA group had the highest fasting plasma glucose levels and the highest insulin levels, even compared to HFD and HFD-BPA groups. At 28 weeks, ipGTT showed that all three tested groups (BPA, HFD and HFD-BPA) acquired higher glucose intolerance compared to the control. In addition, at 28 weeks, insulin sensitivity, measured by intraperitoneal insulin tolerance test (ipITT), showed high 
339 tendency of impairment in BPA, HFD and HFD-BPA groups compared to the control 340 group. Remarkably, the BPA group gained more weight starting from the 18th week

341 compared to the control, and kept increasing the weight until it reached the levels of the

342 HFD and HFD-BPA groups.

343

344

345

346

347

348

349

350

351

352

353

354

355

356

357

358

359

360

361

362

363

364

365

366

367

368

369

370

371

372

373

374

375

376

377

378

379

380

381

382

383

384

In addition, BPA exposure in mice shows an effect on mothers' glucose metabolism during pregnancy, as well as later in life (Alonso-Magdalena et al., 2010). During pregnancy, the treatment with BPA at doses of 10 or $100 \mu \mathrm{g} / \mathrm{kg} /$ day on days of gestation 9-16 (BPA10 and BPA100 mice, respectively) induced a tendency to glucose intolerance measured with ipGTT. In BPA10 mice increased fasting plasma insulin levels were observed (1.38 times higher). In ipITT, both control and BPA10 treated groups, showed only a slight decrease in serum glucose levels, consistent with the physiological insulin resistance in late pregnancy. While BPA10 mice did not alter naturally occurring insulin resistance during pregnancy, in BPA100 mice modestly induced insulin sensitivity was observed. This indicates that BPA10 mice were unable to compensate with their elevated insulin levels to counteract physiological insulin resistance. In addition, in liver BPA treatment reversed insulin-stimulated Akt phosphorylation that occurs in control F0 mice, indicating BPA effects on signaling pathways in liver that are consistent with the strong insulin resistance in these mice. Consequences for mothers later in life included increased body weight four months after delivery, decreased insulin sensitivity measured using ipITT and 2.2 times higher plasma insulin levels after fasting compared to controls. In addition, increased plasma leptin, triglyceride, and glycerol levels were observed in mothers four months after delivery relative to controls. Another study has reported $3 \%$ increase in the body weight during the postpartum period and at 5 and 6 months postpartum found substantial impairment of glucose tolerance and decreased insulin sensitivity. These alterations in glucose metabolism appeared in pregnant, but not in non-pregnant female mice (Alonso-Magdalena et al., 2015). Taken together these data indicate that exposure to BPA during pregnancy produces dysregulated nutrient metabolism later in life. Model animals, therefore, present a valuable source of information on the effect of BPA on insulin resistance, type 2 diabetes and obesity and unveil the connection of environmental estrogens to these phenotypes.

\section{Molecular mechanisms of BPA in promoting endocrine disruption, gestational insulin resistance and diabetes mellitus}

BPA has been first reported to act as a synthetic estrogen in 1936 (Dodds \& Lawson, 1936), well before scientists discovered that it could be polymerized into polycarbonate plastics in the 1950s. As a xenoestrogen and an endocrine-disrupting chemical, BPA has a potential to intervene with any aspect of the hormonal function, to change the hormonal equilibrium and subsequently affect many physiological processes in different tissues. The mechanism of BPA action as a xenoestrogen is thought to be through binding and competing for estrogen receptors, ER-alpha (ER $\alpha)$ and ER-beta $(E R \beta)$ (Figure 1) (Dodds \& Lawson, 1938). However, the interaction of BPA with ER receptors is relatively weak, ranging 2 to 3 orders of magnitude lower compared to estrogens 
385 (relative recruitment ability - RRA; E2 and BPA recruitment to ERa, 100 and 0.073 , 386 respectively; E2 and BPA recruitment to ERB, 100 and 0.75 respectively) (Routledge et 387 al., 2000). Therefore, whether chronic and low-dose BPA exposures function through 388 the ER pathways is still debatable (Safe et al., 2002). Nevertheless, BPA, as well as 389 other xenoestrogens, are indeed able to efficiently and fully displace radioactively 390 labeled $\mathrm{E} 2$ from both $\mathrm{ER} \alpha$ and $\mathrm{ER} \beta$ receptors in a dose dependent manner using a 391 ligand binding assay (Routledge et al., 2000). In addition, recent findings indicate that 392 BPA may act through a receptor named estrogen-related receptor gamma (ERR- $\gamma$ ) 393 (Takayanagi et al., 2006; Okada et al., 2008). ERR-y is a member of estrogen-related receptor class of genes, a subfamily of orphan nuclear receptors, closely related to the ERs. BPA was found to bind ERR-y in both a direct receptor binding assays (FRET), as potently as a tracer for ERR- $\gamma$, and in a cell-based reporter assay where it rescues high constitutive ERR-y activity in HeLa cells treated with an ERR-y inverse agonist 4hydroxytamoxifen (4-OHT) (Okada et al., 2008). Whether BPA exerts its effect on insulin resistance primarily through one of these mechanisms by mimicking estrogen action remains still to be shown, especially since the risk assessment of xenoestrogens based primarily on the reporter gene and binding assays may be insufficient.

In addition, while BPA is capable of displacing E2 when binding to ERa or ER $\beta$ in a dose dependent manner, it has been shown that BPA interacts with a different set of transcriptional co-regulators than E2 (Routledge et al., 2000). As ERs regulate target gene transcription by the association with their co-regulators, interaction with a specific set of transcriptional co-regulators may mean BPA binding induces a unique ER conformation and subsequently recruits a unique set of co-regulators conferring specific gene regulation pattern to the target genes. In addition, BPA demonstrated clear preference for certain co-regulators when bound to ER $\beta$ compared to ER $\alpha$. For example, BPA-ER $\beta$ complex had 500-fold higher recruitment affinity for coactivator TIF2 than BPA-ER $\alpha$ complex (RRA for BPA-ER $\alpha$ and BPA-ER $\beta<0.0001$ and 0.05 respectively), which was directionally equivalent to BPA showing almost 10 -fold greater binding affinity for ER $\beta$ than ER (RRA for ER $\alpha$ and ER 0.073 and 0.75 respectively) (Routledge et al., 2000). BPA can therefore confer specific conformational changes to ER $\beta$ and enhance ER $\beta$ recruitment activity by the order of magnitude compared to its binding effect on ERa. As the main function of E2 binding to ERs is the induction of ER conformational change, in order for the subsequent recruitment of coactivators and assembly of the basal transcription machinery factors, the finding that BPA can efficiently displace E2 from the ER and induce a unique conformational structure of ER (particularly potentiating specific co-factor recruitment to ERß) and the fact that similar has been shown for other xenoestrogens (Routledge et al., 2000), suggests an effective mechanism of BPA action through ER binding.

Other than proposed ER-activation mechanism that involves binding to nuclear receptors, it has been suggested that BPA may exert its effects through other mechanisms, such as through rapid non-genomic (i.e. non-nuclear) pathways (Figure 1) (Welshons et al., 2006; Alonso-Magdalena et al., 2012). Such systems are cell signaling systems with receptors associated to the membrane and the response time of such systems are generally shorter than those mediated by nuclear receptors (Judy \& 
431 Welshons, 2010). In addition, responsiveness can usually be achieved by smaller initial 432 concentrations of the hormone, indicating high level of signal amplification. In 2000 , 433 Nadal et al. demonstrated for the first time that in pancreatic beta cells xenoestrogens, 434 such as BPA, as well as E2, both occupy a common membrane binding site that is distinct from the cytoplasmatic/nuclear ER receptors (Nadal et al., 2000). Subsequently, it has been shown that BPA at picomolar concentrations can cause rapid influx of calcium ion (within $30 \mathrm{sec}$ of administration) followed with a prolactin release in pituitary tumor cells (characterized by the high levels of ERa receptor in the plasma membrane) (Wozniak, Bulayeva \& Watson, 2005). Evidence suggested that BPA alters the conformation of voltage-dependent calcium channels through membrane depolarization, and the prolactin release was fully preventable by removing calcium from the extracellular solution. Similar was detected in mouse pancreatic cells where BPA treatment promoted calcium influx at the nanomolar concentrations (as low as $1 \mathrm{~nm}$ ), with a depolarization-induced influx subsequently causing CREB phosphorylation (Quesada et al., 2002). Cellular responsiveness to lower than nanomolar BPA concentrations $(0.1 \mathrm{~nm})$ was detected also in MCF-7 human breast cancer cells (Walsh, Dockery \& Doolan, 2005). Similarly, it has been found that the BPA exposure in mouse Leydig cells induced activation of protein kinase A and phosphorylation of MAPK only 5 minutes after administration and subsequent rapid induction of Nur77 gene expression that regulates testosterone synthesis (Figure 1), which is an effect that could not be mediated by the prolonged response of nuclear receptors (Song, Lee \& Choi, 2002). Rapid membrane BPA response was confirmed by protein kinase inhibitor $\mathrm{H}-89$ that strongly inhibited BPA-mediated Nur77 gene activation.

The present concept of BPA estrogenicity (mainly based on nuclear receptor activation) demands substantial refinement to incorporate such rapid responses of estrogen receptors found in the membrane (Nadal et al., 2017). It has been shown that ER $\alpha$ and ER $\beta$ could be expressed in both nuclear and membrane cell fractions and could be functional outside the nucleus (Razandi et al., 1999). Transfection of ERa cDNA in CHO cells resulted in the presence of ERa in nuclear and membrane associated cellular fractions and in specific binding of labeled E2 to the $\mathrm{CHO}$ cells. The membrane bound ER fractions had similar dissociation constant as nuclear receptors $(0.287$ and 0.283 $\mathrm{nM}$, respectively), however they represented minor fractions (3\% and $2 \%, \mathrm{ER} \alpha$ and $E R \beta$, respectively) of total receptors in the cell. E2 binding to the membrane ERs resulted in activation of $G$ proteins in the membrane followed by increased adenylate cyclase activity. In 2005, the specific class of steroid membrane receptors named orphan receptor GPR30 (now denoted as G-protein-coupled estrogen receptor, GPER) was discovered in the human breast cancer cells, which could propagate the nonclassical estrogen effects localized at the cell surface (Thomas et al., 2005). Specific E2 binding was detected in SKBR3 breast cancer cells that express GPER, but are missing estrogen receptors, an effect that was reversible with siRNA-mediated decrease in GPER expression. GPER pre-genomic signaling activity was confirmed to be conducted through the plasma membrane G-protein coupled receptor activities, specifically, the activation of adenylyl cyclase (Filardo \& Thomas, 2012). GPER knock-out mice are viable, however they show impaired glucose tolerance, potentiating the role of ER nongenomic signaling in glucose homeostasis (Mårtensson et al., 2009). In addition, it is 
477 speculated that estrogens could bind a large variety of receptors at the plasma

478 membrane surface (Kow \& Pfaff, 2016) and that their effects almost always reproduce

479 the effects of the estrogenic agents that permeate the cell.

480

481

It has been demonstrated that BPA treatment of isolated pancreatic islets, similar to E2, shows the non-monotonic dose response (i.e. an inverted U-shape curve) when insulin content is measured after 48-hour treatment (Alonso-Magdalena et al., 2008). Similar response was observed in vivo when mice were treated with $100 \mu \mathrm{g} / \mathrm{kg}$ or $1 \mathrm{mg} / \mathrm{kg}$ of BPA during 4 days, as low doses of BPA increased insulin content, while the higher doses of BPA exhibited no effect. This non-monotonic dose response was ERa dependent as ERa agonists showed similar pattern of activation. It has been estimated that BPA non-monotonic dose response occurs in $20 \%$ of experiments conducted using BPA and in $30 \%$ of the literature related to BPA the non-monotonic dose-response has been detected (Vandenberg, 2014). The non-monotonic dose response to BPA, while contradicting traditional concepts of toxicology, at the molecular level indeed does not involve BPA acting as a standard toxic chemical, but rather as a hormonal molecule that initiates signaling cascades through the interaction with a hormone receptor. The molecular mechanisms behind such non-linear relationship between the dose and response of EDC may involve receptor saturation, negative feedback loop mechanisms, and/or non-linear process of receptor homodimerization. It has been shown that computational models can accurately predict the appearance of non-monotonic dose response in gene expression within the standard genomic niche of E2 and EDC signaling (Li et al., 2007). Indeed, since a critical step in steroid hormonal action is the dimerization of ligand-bound receptor monomers, computational modeling showed homodimerization of ligand-bound receptors to be an inherently nonlinear process (Figure 2). Furthermore, heterodimerizaton ( $\mathrm{L}_{e n} E R-E R L_{e x}$; ER receptors bound to both endogenous- $L_{e n}$ and exogenous ligands- $L_{e x}$ ) can also induce $U$-shaped responses with the magnitude of response varying with the transcriptional activity of the heterodimer. Model shows that $U$-shaped response arises when the exogenous ligand $L_{e x}$ is an agonist, regardless of the heterodimer being absent, or being pure/partial activator or repressor. On the other side, inverted U-shaped response appears when the heterodimer is a pure or partial activator, regardless whether the exogenous ligand is an agonist or antagonist. Monotonic response, however, only occurs is two simulated scenarios i.e. with the treatment with antagonist when mixed-ligand heterodimer is a repressor or absent.

512

513

514

515

\section{Role of estrogens in gestational insulin resistance}

During pregnancy gestational insulin resistance develops naturally to direct nutrients to the embryo, however the plasma glucose levels may rise to promote gestational diabetes. Insulin resistance perturbs the glucose metabolism and manifests itself in attenuated glucose uptake in the skeletal muscle, white adipose tissue and liver and inadequate suppression of glucose production in the liver (Catalano et al., 2003). Body adapts to this disturbance by increasing the biosynthesis and secretion of insulin through beta-cells located in the pancreatic islets (islets of Langerhans) and by 
523 increasing their cell mass. In the case of GDM beta-cells do not respond adequately to

524 the changes in the organism which leads to elevated blood glucose levels. It is possible

525 that in case of GDM beta cells fail to respond adequately to the natural hormonal

526 signaling during pregnancy, particularly to estrogens (estradiol, estrone and estriol) and

527

528

529

530

531

532

533

534

535

536

537

538

539

540

541

542

543

544

545

546

547

548

549

550

551

552

553

554

555

556

557

558

559

560

561

562

563

564

565

566

567

568 progesterone during the second trimester, when both GDM and increase in estrogens/progesterone concentrations might co-occur (10 fold increase in progesterone, 30 fold increase in estrogens) (Nadal et al., 2009b). In addition, both estrogen and progesterone receptors are expressed in the pancreatic beta-cells (Nadal et al., 2009a) indicating their responsiveness to the pregnancy hormones.

Three major mechanisms that are involved in counteracting insulin resistance during pregnancy are increasing the biosynthesis of insulin, enhancing the sensitivity of pathways for glucose stimulated insulin secretion, and hypertrophy of the beta-cells. Indeed, E2 has been shown to increase glucose stimulated insulin secretion (Nadal et al., 1998). E2 interacts with a membrane-associated receptor and closes ATPdependent $\mathrm{K}^{+}$channels. Subsequently, this depolarizes the plasma membrane and allows the influx of $\mathrm{Ca}^{2+}$, which in turn triggers the release of insulin. When E2 was applied to isolated mouse islets of Langerhans in the absence of glucose stimulation it produced no effect, while in the presence of $8.3 \mathrm{mM}$ glucose an increase in oscillatory electrical activity followed with an oscillatory pattern of $\mathrm{Ca}^{2+}$ concentration were observed, indicating glucose dependent E2 effect. This pattern of $\mathrm{Ca}^{2+}$ oscillations induced pulsatile insulin secretion (Martin, Sanchez-Andres \& Soria, 1995) and a total increase in insulin secretion of $30 \%$. Therefore, E2 exerts its effect on pancreatic beta cells that parallels those observed during normal pregnancy. Wide range of physiological E2 concentrations (100pM-1M) were shown to increase intracellular calcium concentrations, however, even the suboptimal pM concentrations (10pM) were able to show a slight effect. The same effect was observed in vivo (Alonso-Magdalena et al., 2006), when adult male mice were injected twice a day with E2 or a vehicle for four days. Insulin content measured with immunocytochemistry showed that beta-cells from E2 mice had increased staining compared to the vehicle group and therefore possessed higher insulin content in each individual cell that was measured (similar effect was observed for the BPA treatment).

In addition, it has been shown that stimulation of islets isolated from adult mice with E2 at physiological concentrations increases insulin content through promoting insulin mRNA synthesis (Alonso-Magdalena et al., 2008). Insulin mRNA levels increased 1.6 fold only 6 hours after treatment of the islets with E2 (10nM). In the long term stimulation (48 hours) E2 showed similar increase in total insulin content, which fully paralleled the effect of BPA at concentrations of $1 \mathrm{nM}$. BPA titration displayed inverted U-shape dose-response curve indicating the existence of an active concentration range. Similar narrow concentration window of physiological activity was observed for E2, as islets treated with the increasing doses of $\mathrm{E} 2$ for 48 hours showed non-monotonic dose response (inverted U-shape) with the maximal response at E2 concentrations 1-10nM. Consistently, the treatment of pancreatic beta-cell line MIN6 for $2 \mathrm{~h}$ with various concentrations of E2 produced an inverted U-shaped curve (maximum of insulin secretion at E2 concentrations 1-10nM) (Sharma \& Prossnitz, 2011) This indicates that 
569 stabilizing effect on gestational insulin resistance through increasing insulin biosynthesis 570 and secretion in the islets may be highly regulated biological process directed through a 571 narrow range of hormonal concentrations.

572

573

574

575

576

577

578

579

580

581

582

583

584

585

586

587

588

589

590

591

592

593

594

595

596

597

598

599

600

601

602

603

604

605

606

607

608

609

610

611

612

613

614
Glucose homeostasis is primarily controlled at the level of glucose uptake by the skeletal muscle (SM) and white adipose tissues (WAT). Estrogen receptors ERa and ER $\beta$ are expressed in SM and WAT and have opposing effects on expression of GLUT4 glucose transporter. GLUT4 is the main glucose transporter in SM and WAT, and it accelerates the transport of glucose under insulin stimulation (Barnard \& Youngren, 1992; Barros et al., 2009). With insulin binding to its receptors and activation of the tyrosine kinase signaling pathway, GLUT-4 receptors are being transported from the intracellular depos to the sarcolemmal membrane $(\mathrm{SL})$ in SM or plasma membrane in WAT. With GLUT4 being deposited in the membrane, glucose can diffuse into the cell (facilitated diffusion). GLUT4 defective synthesis, glycosylation, translocation and anchorage to the membrane could promote development of insulin resistance. The effect of estrogen on insulin resistance at the level of peripheral tissues is mediated by its two receptors, ER $\alpha$ and $E R \beta$, and sometimes perplexing and contradictory role of estrogen in IR might be explained by the opposing functions of these receptors. ER $\beta$ knockout mice show signs of hypoglycemia, islet hypertrophy and elevated plasma insulin after glucose stimulation, while ERa knock-out mice show completely opposite phenotypes of hyperglycemia and glucose intolerance. In addition, expression of GLUT4 in ER $\beta$ knockout mice is increased, while ERa knockout mice possess lower GLUT4 expression (Barros et al., 2006; Barros, Machado \& Gustafsson, 2006). This indicated that ER $\beta$ activation could have a diabetogenic effect, while ER $\alpha$ action is important for the maintenance of normal glucose homeostasis. Therefore, in case that $E R \alpha$ and ER $\beta$ are exhibiting diametrically opposed effects, cells and tissues with both receptors expressed would respond to $E 2$ in opposite ways depending primarily on the $E R \alpha$ to ER $\beta$ ratio (net effect). In addition, it has been shown that ERa is dominating in the white adipose tissue, while ER $\beta$ is more distributed in the skeletal muscle, where E2 as a net effect might promote insulin resistance (Barros et al., 2009).

The role of estrogens in developing insulin resistance during pregnancy, a feature that chronic bisphenol A exposure is predicted to be mimicking, is somewhat dichotomous, as some studies show protective effect of estrogen on insulin resistance. In a 2012 study, male and ovariectomized female C57BL/6J mice had higher propensity to developing insulin resistance compared to non-ovariectomized females when exposed to a high-fat diet, while the administration of E2 to ovariectomized females reduced insulin resistance in both high and low fat diet groups, as measured by area under curve (AUC) in the glucose tolerance test (Stubbins et al., 2012). The study did not show the effect of E2 on non-ovariectomized females, therefore drawing conclusions only on the stabilizing effect of estrogen on hormone-deficient mice. Similarly, ArKO mice (transgenic mice with inactivated aromatase enzyme, essential for E2 synthesis) developed glucose intolerance and insulin resistance, an effect reversible by E2 (Barros \& Gustafsson, 2011). Likewise, ER $-/$ - mice are glucose intolerant and insulin resistant (Heine et al., 2000). A study in rats found that treatment of male rats with E2 protected against accumulation of fatty acids in pancreatic islets and against pancreatic beta cell 
615 failure (Tiano et al., 2011), therefore preparing the islets for increased insulin production 616 during the pregnancy and gestational insulin resistance. Concurrently, the study

617 proposes ERa or ER $\beta$ receptors as promising therapeutics to prevent beta cell failure in

618 T2D. Estrogens, although with a protective role on beta-pancreatic cells through ER

619 receptors signaling, in peripheral tissues like SM were predicted to promote insulin

620 resistance via $E R \beta$ net effect (ratio $E R \beta / E R \alpha$ ) (Barros et al., 2009). However, some

621 studies showed that E2 treatment might result only in slight decrease in glucose uptake

622 in SM without insulin and with significant improvement of muscle glucose uptake with

623 insulin treatment, which suggests ERa dominance over ER $\beta$ in SM (Gorres et al., 2011;

624 Inada et al., 2016), leading to contention within the field.

625

626 On the other side, insulin resistance and hyperinsulinemia are common among women

627

628

629

630

631

632

633

634

635

636

637

638

639

640

641

642

643

644

645

646

647

648

649

650

651

652

653

654

655

656

657

658

659

660 consuming oral contraceptives containing estrogens and during pregnancy, and diminished peripheral glucose uptake was observed among normal subjects treated with ethinyl estradiol (Polderman et al., 1994). Association has been found between insulin resistance and E2 levels in obese children (Lin \& Ji, 2016). Studies suggest that in humans the lipolytic effect of placental lactogen directs maternal metabolism toward lipids, rather than glucose utilization, in the same time adding to the preservation of glucose for the fetus (Baz, Riveline \& Gautier, 2016). In non-diabetic women, employing the intravenous glucose tolerance test in 296 oral contraceptive users and 95 nonusers, estrogen based contraceptives reduced the glucose elimination constant and reduced insulin sensitivity by $30-40 \%$ (Godsland et al., 1992). Other studies showed that users of oral contraceptives with synthetic estrogen had up to $61 \%$ higher plasma glucose levels, up to $40 \%$ higher insulin response and up to $40 \%$ higher $C$ peptide response, a method to determine residual insulin secretion (Godsland et al., 1990). More recent metaanalysis showed less disturbance in carbohydrate metabolism (Lopez, Grimes \& Schulz, 2014), potentially due to the change in composition of contraceptives that contain fewer estrogen content.

\section{Strong cross-generational transmission of BPA effects to male offspring}

In 2010 came the first study in mice that showed that treatment of pregnant females with low doses of BPA could in F1 male offspring provoke glucose intolerance, insulin resistance and altered beta-cell function (Alonso-Magdalena et al., 2010). The pancreatic islets from male offspring showed abnormal $\mathrm{Ca}^{2+}$ signaling and increased insulin secretion. Decreased bromodeoxyuridine (BrdU) incorporation into insulinproducing cells was detected in the male offspring, indicating absence of proliferation. An indication of non-monotonic dose response was observed as insulin sensitivity was evidently impaired in F1-BPA10 male offspring (slight alteration in 3-months old mice, significant alteration in 6-months old mice), however no significant alteration of insulin sensitivity was detected in F1-BPA100 males. Similarly, both serum insulin levels and glucose-stimulated insulin secretion in vivo and ex vivo (using isolated islets) were higher in F1-BPA10 males compared to the control, while the same effect was not observed in F1-BPA100 male mice, again suggesting non-monotonic dose response.

Similar non-monotonic dose response was observed in the increase of intracellular $\mathrm{Ca}^{2+}$ 
661 in isolated islets after glucose stimulation (both $7 \mathrm{mM}$ and $16 \mathrm{mM}$ glucose) that was 662 detected in the F1-BPA10, but not F1-BPA100 males. In addition, F1-BPA10 male mice 663 weighted $3 \%$ more than the control mice, while F1-BPA100 were $4.5 \%$ lighter at birth 664 than controls. On the other side, the glucose tolerance was altered in both F1-BPA10 665 and F1-BPA100 male mice, however with a slight decrease in AUC in F1-BPA100 666 males. The phenotype of altered glucose metabolism in male offspring was confirmed 667 subsequently in additional studies (Wei et al., 2011; Angle et al., 2013; García-Arevalo

In addition, the interaction of two environmental stimuli, BPA and high fat diet (HFD) has been examined (García-Arevalo et al., 2014). The group of F1 male mice exposed to BPA in utero increased their weight starting from 18 weeks old and reached the HFD and HFD-BPA groups at week 28. The BPA group showed similarities to both HFD and HFD-BPA groups in exhibiting fasting hyperglycemia and glucose intolerance (slight increase in AUC at 17 weeks, and reaching HFD and HFD-BPA groups at 28 weeks). Other studies have found similar tendencies of increased body weight, elevated serum insulin levels and impaired glucose tolerance in F1-BPA offspring, which were elevated and accelerated with the introduction of a high fat diet (Wei et al., 2011). Consistent with the BPA-HFD interaction, F1-HFD-BPA mice showed severe metabolic syndrome, including obesity, dyslipidemia, hyperglycemia, hyperinsulinemia, and glucose intolerance. However, the effects were present on lower BPA doses, but were absent on higher BPA doses indicating that, even though it triggered adverse metabolic effects of BPA, HFD did not influence the non-monotonic dose response to BPA. Another study showed that the fetal and perinatal treatment with BPA was more detrimental than neonatal (Liu et al., 2013). The effect of BPA on blood glucose homeostasis in 6 months old male mice was pronounced in the group with fetal exposure from day 6 of pregnancy until postnatal day (PND) 0 , while only modest effects were observed in the group with neonatal exposure (PND0-PND21), suggesting a critical timeframe when BPA can exert its effects during the embryological development.

Furthermore, the a plethora of diverse effects on male offspring were detected (including a decrease in glucose tolerance and serum adiponectin and an increase in body and liver mass, abdominal adipocyte number, and serum leptin and insulin levels). This occurred at the doses of BPA below the predicted 'no adverse effect level' (NOAEL), while doses 10-fold above NOAEL did not show any significant effect, confirming the non-monotonic dose response (Angle et al., 2013). In addition, the BPA exposure might predispose offspring to the fatty liver disease, a part of the metabolic syndrome symptoms (Jiang et al., 2014). In Wistar rats, with perinatal exposure to BPA, at 26 weeks of age extensive fat accumulation in liver was observed, as well as elevated serum alanine aminotransferase (ALT), the indicator of liver damage. Milder effects were observed at 3 weeks, i.e. a decrease in mitochondrial respiratory complex (MRCI, MRCIII) activity and altered expression levels of genes involved in mitochondrial fatty acid metabolism, while at 15 weeks an infiltration of liver cells with fat (steatosis), as well as upregulation of lipogenesis genes and increased levels of reactive oxygen species (ROS, indicative of the loss of mitochondrial function) were observed. 
707

708

709

710

711

712

713

714

715

716

717

718

719

720

721

722

723

724

725

726

727

728

729

730

731

732

733

734

735

736

737

738

739

740

741

742

743

744

745

746

747

748

749

750

751

752

It has been shown, using different animal models, that the prenatal exposure to BPA leads to severe glucose intolerance, insulin resistance and hyperinsulinemia during postnatal life (Alonso-Magdalena et al., 2015). In mice, BPA-treated pregnant females (10 $\mathrm{\mu g} / \mathrm{kg}$ on days 9-16 of gestation) produced male progeny that showed altered glucose metabolism at 17 and 28 weeks of age (García-Arevalo et al., 2014), therefore confirming that the treatment with endocrine-disrupting chemicals leads to the perturbation of glucose metabolism of pregnant females that is being efficiently transmitted to the offspring. Recently, it has been shown that BPA treatment of pregnant female mice (10 and $100 \mu \mathrm{g} / \mathrm{kg}$ per day) in male offspring promotes increased expression of cell division genes in the beta cells of pancreas followed with increased pancreatic beta-cell growth and increased insulin levels at postnatal days 0, 21 and 30 (García-Arévalo et al., 2016). Conversely, at postnatal day 120 beta cell mass diminished and mice showed increased fasting glucose levels and tendency towards glucose intolerance. Therefore, parental BPA exposure in mice leads to the surplus of insulin signaling during early life in male offspring that could advance into the impaired glucose tolerance of adulthood. Such perturbations in glucose metabolism induced by EDC could therefore be actively transmitted to the developing mouse embryo and appear as long-term consequences later in life (Figure 3). A 2016 study in humans showed association of prenatal creatinine-adjusted urinary BPA concentrations with BMI levels and waist circumference in male children of 1-4 years of age (Vafeiadi et al., 2016). For female offspring, prenatal urinary BPA was inversely associated with BMI and adiposity measures, confirming similar gender-related trends that were observed in animal studies.

\section{BPA effects detected in female offspring in mice}

Interestingly, even though the effects of BPA exposure in mice are usually observed in the male offspring, multiple studies have reported the occurrence of strong effects in the female offspring. In one study, female offspring showed altered blood glucose homeostasis, as measured with intraperitoneal glucose tolerance test (ipGTT) (Liu et al., 2013). At 3 months, the response to glucose challenge was evident in the group with fetal BPA exposure from day 6 of pregnancy until PND 0 (P6-PND0) compared to the groups with preimplantation (P1-P6), neonatal (PND0-PND26) or fetal plus neonatal (P6- PND26) exposure, indicating the existence of the critical window of exposure similar to the effect on male offspring. At 6 months, the effects are significant for both P1-P6 and P6-PND0 groups, however the intensity of alterations in glucose homeostasis decreases. Finally, at 8 months, AUC in ipGTT in all groups did not differ from the control group of mice. In addition, P6-PND0 female offspring at 3 months showed increasing fasting insulin levels, while at 6 months they showed increased fasting glucose levels. The insulinogenic index $\left(\Delta \mathrm{I}_{0-30} / \Delta \mathrm{G}_{0-30}\right)$, which is measuring insulin release in response to the glucose load, was decreased in 3 months old females from the P6-PND0 group, and then improved in 6 and 8 months old females. A study in rats showed similar profiles between male and female offspring rats in fasting blood glucose and fasting serum insulin at $3,9,15$, and 26 weeks after perinatal exposure to 
753

754

755

756

757

758

759

760

761

762

763

764

765

766

767

768

769

770

771

772

773

774

775

776

777

778

779

780

781

782

783

784

785

786

787

788

789

790

791

792

793

794

795

796

797

798

$50 \mu \mathrm{g} / \mathrm{kg}$ per day of BPA (Wei et al., 2011). The group of HFD-BPA female rats showed higher fasting blood glucose and fasting serum insulin levels starting from 9 weeks of age compared to the HFD group, indicating the interaction of BPA exposure with the HFD phenotype. In addition, at 26 weeks, female BPA-exposed offspring on a normal diet, similar to the male offspring, had greater glucose and insulin AUC in OGTT and ITT compared to controls. Concordantly, the interaction of HFD phenotype and BPA exposure could be observed in females at 26 weeks in OGTT AUC.

In a 2017 study, fetal livers were collected from the F1 generation (embryonic day E18.5) exposed to BPA in utero from E7.5 to E18.5, and gene expression of key hepatocyte maturation markers was assessed (DeBenedictis, Guan \& Yang, 2016). Particularly, in female mice changes were prominent and involved decreasing levels of mature hepatocyte markers, such as albumin and glycogen synthase (reduced $65 \%$ and $40 \%$, respectively), decreased levels of C/EBP-alpha, the master transcription factor of hepatocyte maturation (reduced 50\%), and increased levels of immature hepatocyte marker, a-fetoprotein (increased $43 \%$ ). In addition, the markers of proliferation (PCNA) were elevated $(40 \%$ increase) and the markers of apoptosis (caspase- 3 ) were decreased ( $40 \%$ decrease). This suggests that BPA reduces maturation and alters the balance of proliferation and apoptosis in fetal hepatocytes, in a similar direction as observed in the pancreatic islets in F1 mice (García-Arévalo et al., 2016), where upregulated genes enrich in gene ontologies related with cell cycle, mitosis and cell division.

\section{Epigenetic modifications of DNA as a mechanism of BPA-induced transgenerational effects}

In another study, it has been shown that BPA might promote epigenetic changes that are associated with the transmission of perturbed carbohydrate metabolism phenotype to offspring (Susiarjo et al., 2015). Exposure of BPA in C57BL/6 mothers produced multigenerational metabolic abnormalities and stable inheritance of changes in DNA methylation at the imprinted lgf2 gene locus, a well-studied gene locus involved in fetal growth and recently shown to alter adult energy metabolism, fat deposition and obesity (Jones, Levorse \& Tilghman, 2001). Study established altered body mass, glucose tolerance, and insulin secretion in male, but not female, F1 mice and the effect on F2 generation was estimated to originate from the exposure to BPA in developing germ cells. Previous study has shown that BPA can alter the methylation levels of differentially methylated regions (DMR) and that it promotes loss of monoallelic expression of the Snrpn, Igf2 and Kcnq1ot1 genes in a tissue specific manner in F1 offspring (placental and embryonic tissue) (Susiarjo et al., 2013). Loss of imprinting was highly specific for placenta as 13/28 placentas showed loss of imprinting (LOI) compared to $0 / 23$ controls for the Snrpn gene. On the contrary, at the Igf2 gene locus, LOI was found in $7 / 28$ embryos compared to $0 / 23$ controls, while it has been absent in placentas. Repressed maternal lgf2 allele was shown to increase its expression up to $68.9 \%$ of the total Igf2 expression. Analysis of DNA methylation at the $16 \mathrm{CpG}$ sites in the Snrpn promoter, which is hypermethylated on the maternal allele, showed reduction 
799 in methylation levels in upper dose BPA exposed placentas (observed methylation 800 levels of the maternal allele were 53.8\% lower than those of controls), while similar 801 trend was observed in the embryos. On the Igf2 locus, DMR1 region showed

802 significantly increased methylation levels in embryos (45.6\% in controls vs. $55.7 \%$ in

803 upper dose BPA in embryos, $\mathrm{p}<0.05$; trend not observed in placentas), which was

804 consistent with previous association of the gain of DNA methylation with

805 biallelic lgf2 expression (Figure 4). To determine whether genomic imprinting effects

806 were present in the F2 offspring in the absence of further exposure, F1 females were

807 mated to unexposed males, however biallelic expression of the Igf2 gene was not

808 observed (Susiarjo et al., 2015). Nevertheless, BPA treated embryos in F2 generation

809 showed significant overexpression of Igf2 gene compared to controls. Similar to the

810 BPA phenotype, $\mathrm{H}^{19^{\Delta 3.8 /+}}$ male mice with the imprinted control locus (ICR) deletion

811 showed increased glucose intolerance, increased body weight and body fat content,

812 indicating that BPA might exert its effect partly through epigenetic changes at the lgf2

813 locus.

814

815 Similarly, another study has shown that BPA can exert multigenerational effects, as the

816 F2 generation rats were found to exhibit glucose intolerance and insulin resistance in

817 ipGTT and ipITT and decreased expression of Gck (glucokinase) gene in the liver, and

818 this effect was estimated to be epigenetic. The Gck promoter in the hepatic tissue in F2

819 generation rats exhibited fully methylated status in the all five $\mathrm{CpG}$ sites upstream of the

820 promoter (located up to $314 \mathrm{bp}$ upstream), compared to the unmethylated status in the

821 control rats (Li et al., 2014). Similar trend of BPA induced Gck promoter

822 hypermethylation was observed in F1 generation in 3 week old offspring rats and more

823 pronounced increase of Gck methylation was observed in 21 week old rats (Ma et al.,

824 2013). In addition, in both studies, BPA was shown to induce changes in global DNA

825 methylation (decrease in DNA methylation, 84.3\% BPA-treated F2 offspring vs $90.1 \%$

826 controls) implicating long term epigenetic effects.

827

828

829

830

831

832

833

834

835

836

837

838

839

840

841

842

843

844

\section{Epidemiological studies connecting BPA and T2D}

Multiple epidemiological studies have linked BPA exposure (mainly measured as urinary BPA concentrations) with T2D or prediabetes occurrence (diagnosed using lab tests of fasting blood glucose or $\mathrm{HbA1c}$, self-reports, previous doctor diagnosis, or current use of diabetic drugs) (Sowlat et al., 2016). A study of 3,516 subjects from the National Health and Nutritional Examination Survey (NHANES) 2003-2008 found a positive correlation between higher urinary BPA and prediabetes (fasting plasma glucose), and correlation was independent of confounders including body mass index, alcohol intake, blood pressure and serum cholesterol (Sabanayagam, Teppala \& Shankar, 2013). When T2D was examined within the participants of NHANES, a correlation was observed with odds ratio (OR) of 1.39, however only for the cycle 2003-2004 (Lang et al., 2008; Silver et al., 2011, pp. 2003-2008). Another study of NHANES participants found multivariable-adjusted OR of 1.68 when comparing $1^{\text {st }}$ quartile of urinary BPA concentrations with $4^{\text {th }}$ quartile $(p=0.002)$ (Shankar $\&$ Teppala, 2011). In addition to measured urinary BPA concentrations, a study of 2581 subjects in Thailand that 
845 involved blood (serum) BPA levels has found a significant correlation between serum

846 BPA levels and T2D ( $\mathrm{OR}=1.83$ and 1.88, for women and men respectively) (Aekplakorn, 847 Chailurkit \& Ongphiphadhanakul, 2015). However, other epidemiological studies failed

848 to find a statistically significant correlation of BPA levels and T2D. For example, a study

849 involving 3423 subjects in China measured urinary BPA concentrations and found

850 slightly increased OR for T2D (OR=1.30, 1.37, in second and fourth BPA quartile,

851 respectively), but not third quartile, and the overall association was not significant (Ning

852 et al., 2011). Similarly, a cross-sectional study of Korean adults showed increased

853 adjusted odds ratio for T2D in the upper BPA quartile $(\mathrm{OR}=1.89)$, however, this

854 association did not reach statistical significance (Kim \& Park, 2013). Therefore, the

855

856

857

858

859

860

861

862

863

864

865

866

867

868

869

870

871

872

873

874

875

876

877

878

879

880

881

882

883

884

885

886

887

888

889

890

\section{BPA effects in promoting cardiovascular diseases}

The previous studies on BPA treatment in animal-models found evidence of interference on the mechanisms underlying insulin signaling and diabetes, while the underlying mechanisms of association of cardiovascular diseases are not evident. In a 2008 study (Lang et al., 2008), 1455 adults from the NHANES 2003-2004 study (694 men and 761 women), 18-74 years of age, have had their urinary BPA and creatinine levels measured. Regression association was adjusted for the creatinine concentration in urine, as well for a set of standard factors, such as age, sex, ethnicity, education, and body mass index. Tested samples provided $80 \%$ power and detected that higher BPA concentrations in urine were associated with cardiovascular diagnoses in models adjusted for age and sex and in a fully adjusted model (OR=1.39 per 1-SD increase in BPA, 95\% confidence interval: 1.18-1.63, full adjustment pval=0.001). Similarly, in the study of 1493 participants of the NHANES 2005-2006 elevated urinary BPA concentrations were correlated with coronary artery disease $(C A D)(O R=1.33)$ (Melzer et al., 2010, p. 6). In mice, BPA exposure has been linked to the increase in production of a strong helper T type 1 (Th-1) type cytokine (IFN-gamma) in lymphocytes (Youn et al., 2002), which given the role of Th-1 immunity and inflammation in atherosclerosis and CAD (Engelbertsen \& Lichtman; Pjanic et al., 2016; Kim et al., 2017) might mechanistically bridge the link to CAD. Whether BPA exerts it effect on cardiovascular diseases through its loose binding to the estrogen receptor or via binding to the estrogen related receptors, and whether this is a shared downstream mechanism with the effect on insulin resistance remains to determined, especially considering that estrogen receptor signaling exhibits pleiotropic effects on the cardiovascular system.

\section{Proposed BPA involvement in other phenotypes}

In epidemiological studies, bisphenol A exposure has been linked to various disorders in humans, such as insulin resistance and diabetes (Shankar \& Teppala, 2011), cardiovascular diseases (Lang et al., 2008), and obesity (Wang et al., 2012). In a 2008 study (Lang et al., 2008), higher BPA concentrations were associated with diabetes 
891 mellitus (OR=1.39 per 1-SD increase in BPA, 95\% confidence interval: 1.21-1.60, full 892 adjustment pval < 0.001). In addition, in the same study, out of 8 blood serum analytes, 893 urinary BPA was associated with clinically abnormal concentrations of the liver enzymes 894 Y-glutamyltransferase (OR=1.29 per 1-SD increase in BPA, 95\% Cl: 1.14-1.46, full 895 adjustment pval <0.001), alkaline phosphatase (OR=1.48, 95\% Cl: $1.18-1.85$, pval $=$ 8960.002 ) and lactate dehydrogenase ( $p v a l=0.04$ ). As no significant associations with the 897 other common disorders were found, the specificity of the associations to insulin 898 resistance, diabetes and cardiovascular diseases implicated BPA in modulation of 899 common mechanisms perturbed in these diseases. On the other side, the association of BPA and the enzymes present in liver, specifically y-glutamyltransferase and lactate dehydrogenase, was preserved in a cohort without cardiovascular diseases or diabetes (glutamyltransferase $\mathrm{OR}=1.22,95 \% \mathrm{Cl}: 1.02-1.45$, pval= 0.03 ; lactate dehydrogenase OR=1.31, 95\% Cl: 1.06-1.62, pval=0.01) (Lang et al., 2008), suggesting that mechanisms underlying the BPA effect on liver are distinct from the cardiovascular and insulin resistance/diabetes effects and therefore exclude reverse causation of these diseases. In addition, in patients with BMI less than 25, BPA preserved significant association with $\gamma$-glutamyltransferase ( $p v a l=0.03$ ).

\section{Discussion}

In the last two decades, bisphenol A has been a target of strong public and scientific scrutiny. The number of papers on BPA available on Pubmed reaches 10,668, with several hundred papers published each year. An overwhelming body of knowledge has accumulated since, both mechanistic, in animal models, and epidemiological, that has contributed to our better understanding of the implications that the widespread and chronic exposure of human population to BPA carries. Even though BPA properties as estrogen mimicking molecule have been discovered in 1936 (Dodds \& Lawson, 1936) and 1938 (Dodds \& Lawson, 1938), its widespread use as a synthetic polymer unit, starting from the late 1950s, hasn't been influenced by the fact that it might behave as an endocrine-disrupting chemical. Driven by the industrial tendencies and novel emerging markets, BPA based polycarbonate polymers have infiltrated almost every aspect of the human life, including food containers, baby and water bottles, can and glass linings, various medical and dental devices, eyeglass lenses, and finally the epoxy lining of water pipes and tanks, making the large majority of human population chronically exposed to the low levels of this synthetic chemical.

Whether the widespread use of BPA in the contemporary human environment is related to the expansion of insulin resistance, diabetes and obesity-related diseases is unclear. One can contemplate that this is most probably not a direct or unique cause of the elevated fasting plasma glucose levels, insulin resistance and diabetes expansion in the human populations, however the time frames of the diabetes expansion and the use of plastic bottles coincide, hence, given the experimental findings, the question becomes more quantitative than qualitative. The prevalence of hyperglycemia and diabetes are rising globally since 1980 with a mean fasting plasma glucose level increasing 0.09 $\mathrm{mmol} / \mathrm{L}$ per decade, while the number of people with diabetes increased from 153 million in 1980 to 347 million in 2008, more than doubling in size during 3 decades 
937 (Danaei et al., 2011). The level of BPA exposure in human populations depends

938 primarily on how chemically effective the hydrolysis and photo-degradation of

939 polycarbonate polymers are in their natural environment and that depends on the

940

941

942 content, stability and storage conditions of plastic polymers and coating materials. On higher temperatures, increased hydrolysis leads to the excess of leached BPA in the neighboring environment. Certain polycarbonate plastics and coatings may represent

943

944

945 common sources of leaching BPA levels, e.g. food containers that will be exposed to higher temperatures in microwave ovens. Therefore, unknowingly humans may further increase the hydrolysis of polycarbonates and subsequently their exposure to BPA by,

946

947

948

949

950

951

952

953

954

955

956

957 e.g. microwaving food in plastic containers, refilling plastic water bottles or leaving plastic water bottles in the sun exposed to light, with BPA polymers undergoing photooxidative degradation.

BPA traces have been detected leaching from the polycarbonate plastic products, as well as present in various human tissues. BPA environmental levels correspond to the tissue levels, appearing in the concentrations of the same order of magnitude $\left(\mathrm{ng} \mathrm{ml}^{-1}\right)$, indicating effective transfer from the environment to the human internal organs and tissues. BPA has been detected in human serum with concentrations up to $4.4 \mathrm{ng} \mathrm{ml}^{-1}$ (Vandenberg et al., 2007) and urine with detection rates up to $97.5 \%$ (Yang et al., 2006). As tissues that exhibited the highest BPA concentrations up to the levels of 11.2 $\mathrm{ng} \mathrm{ml}^{-1}$ were related to the embryo development, such as placenta, umbilical cord, and

958

959

960

961

962

963

964

965

966

967

968

969

970

971 amniotic fluid, as well as to the maternal influence of postnatal development of infants, like breast milk and colostrum, it may not be surprising that experimental studies in mice, as well as epidemiological studies in humans, showed pronounced transgenerational effects of BPA. The question of mechanism for gender-related differences of the BPA effects in offspring still remains open, as to why predominantly male offspring exhibit increased insulin resistance, while female offspring show negative BMI correlation. The explanation may come from a gender-related differences in BPAprocessing liver enzyme levels and subsequent BPA clearance from the organism. For instance, it has been shown that female rats harbor higher UDP-

glucuronosyltransferase liver levels, as well more effective BPA glucuronidation reaction that eliminates BPA from the organism (Takeuchi et al., 2004).

Skepticism could emerge due to the fact that BPA has much lower affinity for estrogen receptors, therefore questioning whether its effects are indeed negligible. However, it

972 may be possible that effects of prolonged exposure to low affinity binders mimic the 973 short term effect of high affinity binders, providing mechanistic explanation for direct 974 BPA action. Indeed, low affinity binders may have profound effects on the pathogenesis of obesity and insulin resistance, as shown in the case of insulin-like growth factor binding proteins (IGFBPs) comprising both insulin-like growth factor (IGF) high-

977

978

979

980

981

982 and low-affinity binders (Kim et al., 1997; Ruan \& Lai, 2010).

As it has been shown that in various in vivo and in vitro experiments BPA effects follow the non-monotonic dose response (i.e. the inverted U-shape curve), a narrow concentration range might exist that is critical for the BPA action. Similarly, the narrow window of developmental stages exists during which BPA will exert its maximal effect 
983 (e.g. P6-PND0). Combined with the gender related differences, there might exist a 984 specific set of conditions under which BPA exerts its maximal biological and 985 physiological effect (Figure 5). Therefore, the complete elucidation of the maximal BPA 986 effects on offspring may be limited to the very specific set of experimental conditions. In 987 addition, the discovery of BPA mechanism that involves epigenetic modifications (i.e. DNA methylation) reveals the complexity of the mechanism responsible for the appearance of BPA phenotype in subsequent generations.

Even though at present day BPA-free plastic products are getting more available, e.g. BPA-free water bottles, the use of BPA-free polymers has not reached widespread levels and in many cases BPA is simply substituted with one of its analogues, BPS or BPF, that may exhibit similar behavior to BPA. In addition, the level of public education on this subject remains relatively poor and the amount of BPA present in the environment still remains at the levels of a substantial health threat. Consistently, it will take years of regulation of environmental and industrial BPA levels to achieve reduced BPA concentrations to the pre-industrial levels or its complete elimination.

BPA may have an effect that needs to be deciphered from the existing data to prevent its long-term negative impact. As once, unaware of the health risks, Roman populations had been poisoned gradually by an increased lead content in the water, through utilization of leaded pipes in their water distribution network (Delile et al., 2014), which subsequently contributed to the decline of Roman empire, the environmental and health toll of BPA plastics in the human environment needs to be addressed thoughtfully in the modern world. Further experimental and epidemiological efforts are necessary to fully establish a magnitude of potentially hazardous effects of BPA in humans, and its association to insulin resistance and diabetes, as well as other human diseases.

1013 Aekplakorn W., Chailurkit L., Ongphiphadhanakul B. 2015. Relationship of serum bisphenol A with diabetes in the Thai population, National Health Examination Survey IV. Journal of

\section{References}

1016

1017

1018

1019

1020

Diabetes 7:240-249. DOI: 10.1111/1753-0407.12159.

Aerts L., Van Assche FA. 2006. Animal evidence for the transgenerational development of diabetes mellitus. The International Journal of Biochemistry \& Cell Biology 38:894-903.

DOI: 10.1016/j.biocel.2005.07.006.

Alonso-Magdalena P., García-Arévalo M., Quesada I., Nadal Á. 2015. Bisphenol-A Treatment During Pregnancy in Mice: A New Window of Susceptibility for the Development of 
1021

1022

1023

1024

1025

1026

1027

1028

1029

1030

1031

1032

1033

1034

1035

1036

1037

1038

1039

1040

1041

1042

Diabetes in Mothers Later in Life. Endocrinology 156:1659-1670. DOI: 10.1210/en.2014-1952.

Alonso-Magdalena P., Morimoto S., Ripoll C., Fuentes E., Nadal A. 2006. The Estrogenic Effect of Bisphenol A Disrupts Pancreatic $\beta$-Cell Function In Vivo and Induces Insulin Resistance. Environmental Health Perspectives 114:106-112. DOI: 10.1289/ehp.8451.

Alonso-Magdalena P., Ropero AB., Carrera MP., Cederroth CR., Baquié M., Gauthier BR., Nef S., Stefani E., Nadal A. 2008. Pancreatic insulin content regulation by the estrogen receptor ER alpha. PloS One 3:e2069. DOI: 10.1371/journal.pone.0002069.

Alonso-Magdalena P., Ropero AB., Soriano S., García-Arévalo M., Ripoll C., Fuentes E., Quesada I., Nadal Á. 2012. Bisphenol-A acts as a potent estrogen via non-classical estrogen triggered pathways. Molecular and Cellular Endocrinology 355:201-207. DOI: 10.1016/j.mce.2011.12.012.

Alonso-Magdalena P., Vieira E., Soriano S., Menes L., Burks D., Quesada I., Nadal A. 2010. Bisphenol A exposure during pregnancy disrupts glucose homeostasis in mothers and adult male offspring. Environmental Health Perspectives 118:1243-1250. DOI: 10.1289/ehp.1001993.

Angle BM., Do RP., Ponzi D., Stahlhut RW., Drury BE., Nagel SC., Welshons WV., BeschWilliford CL., Palanza P., Parmigiani S., vom Saal FS., Taylor JA. 2013. Metabolic disruption in male mice due to fetal exposure to low but not high doses of bisphenol A (BPA): Evidence for effects on body weight, food intake, adipocytes, leptin, adiponectin, insulin and glucose regulation. Reproductive Toxicology 42:256-268. DOI: 10.1016/j.reprotox.2013.07.017. 
1043 Barnard RJ., Youngren JF. 1992. Regulation of glucose transport in skeletal muscle. FASEB 1044 journal: official publication of the Federation of American Societies for Experimental $1045 \quad$ Biology 6:3238-3244.

1046 Barros RPA., Gabbi C., Morani A., Warner M., Gustafsson J-Å. 2009. Participation of ER $\alpha$ and 1047 ER $\beta$ in glucose homeostasis in skeletal muscle and white adipose tissue. American 1048 Journal of Physiology - Endocrinology and Metabolism 297:E124-E133. DOI: 10.1152/ajpendo.00189.2009.

Barros RPA., Gustafsson J-Å. 2011. Estrogen Receptors and the Metabolic Network. Cell 1051 Metabolism 14:289-299. DOI: 10.1016/j.cmet.2011.08.005.

Barros RPA., Machado UF., Gustafsson J-A. 2006. Estrogen receptors: new players in diabetes mellitus. Trends in Molecular Medicine 12:425-431. DOI:

Barros RPA., Machado UF., Warner M., Gustafsson J-A. 2006. Muscle GLUT4 regulation by estrogen receptors ERbeta and ERalpha. Proceedings of the National Academy of Sciences of the United States of America 103:1605-1608. DOI: 10.1073/pnas.0510391103.

Baz B., Riveline J-P., Gautier J-F. 2016. ENDOCRINOLOGY OF PREGNANCY: Gestational diabetes mellitus: definition, aetiological and clinical aspects. European Journal of Endocrinology 174:R43-R51. DOI: 10.1530/EJE-15-0378.

1062 Bento AP., Gaulton A., Hersey A., Bellis LJ., Chambers J., Davies M., Krüger FA., Light Y., 1063 Mak L., McGlinchey S., Nowotka M., Papadatos G., Santos R., Overington JP. 2014. The ChEMBL bioactivity database: an update. Nucleic Acids Research 42:D1083-D1090. DOI: $10.1093 /$ nar/gkt1031. 
1066 Berge TLL., Lygre GB., Jönsson B a. G., Lindh CH., Björkman L. 2017. Bisphenol A

1067

1068

1069

1070

1071

1072

1073

1074

1075

1076

1077

1078

1079

1080

1081

1082

1083

1084

1085

1086

concentration in human saliva related to dental polymer-based fillings. Clinical Oral Investigations. DOI: 10.1007/s00784-017-2055-9.

Biedermann S., Tschudin P., Grob K. 2010. Transfer of bisphenol A from thermal printer paper to the skin. Analytical and Bioanalytical Chemistry 398:571-576. DOI: 10.1007/s00216010-3936-9.

Brede C., Fjeldal P., Skjevrak I., Herikstad H. 2003. Increased migration levels of bisphenol A from polycarbonate baby bottles after dishwashing, boiling and brushing. Food Additives and Contaminants 20:684-689. DOI: 10.1080/0265203031000119061.

Buchanan TA., Xiang AH., Peters RK., Kjos SL., Marroquin A., Goico J., Ochoa C., Tan S., Berkowitz K., Hodis HN., Azen SP. 2002. Preservation of pancreatic beta-cell function and prevention of type 2 diabetes by pharmacological treatment of insulin resistance in high-risk hispanic women. Diabetes 51:2796-2803.

Calafat AM., Kuklenyik Z., Reidy JA., Caudill SP., Ekong J., Needham LL. 2005. Urinary Concentrations of Bisphenol A and 4-Nonylphenol in a Human Reference Population. Environmental Health Perspectives 113:391-395. DOI: 10.1289/ehp.7534.

Catalano PM., Kirwan JP., Haugel-de Mouzon S., King J. 2003. Gestational diabetes and insulin resistance: role in short- and long-term implications for mother and fetus. The Journal of Nutrition 133:1674S-1683S.

Cheung NW., Byth K. 2003. Population health significance of gestational diabetes. Diabetes Care 26:2005-2009. 
1087 Chiefari E., Arcidiacono B., Foti D., Brunetti A. 2017. Gestational diabetes mellitus: an updated 1088 overview. Journal of Endocrinological Investigation:1-11. DOI: 10.1007/s40618-016-

$1089 \quad 0607-5$.

1090 Clark DT., Munro HS. 1984. Surface and bulk aspects of the natural and artificial photo-ageing 1091 of Bisphenol A polycarbonate as revealed by ESCA and difference UV spectroscopy. 1092 Polymer Degradation and Stability 8:195-211. DOI: 10.1016/0141-3910(84)90018-1.

1093 Collin S., Bussière P-O., Thérias S., Lambert J-M., Perdereau J., Gardette J-L. 2012.

1094 Physicochemical and mechanical impacts of photo-ageing on bisphenol a polycarbonate.

1095 Polymer Degradation and Stability 97:2284-2293. DOI:

$1096 \quad$ 10.1016/j.polymdegradstab.2012.07.036.

1097 Damm P., Houshmand-Oeregaard A., Kelstrup L., Lauenborg J., Mathiesen ER., Clausen TD.

1098 2016. Gestational diabetes mellitus and long-term consequences for mother and

1099 offspring: a view from Denmark. Diabetologia 59:1396-1399. DOI: 10.1007/s00125-

$1100 \quad 016-3985-5$.

1101 Danaei G., Finucane MM., Lu Y., Singh GM., Cowan MJ., Paciorek CJ., Lin JK., Farzadfar F.,

1102 Khang Y-H., Stevens GA., Rao M., Ali MK., Riley LM., Robinson CA., Ezzati M.,

1103 Global Burden of Metabolic Risk Factors of Chronic Diseases Collaborating Group

1104 (Blood Glucose) 2011. National, regional, and global trends in fasting plasma glucose

1105 and diabetes prevalence since 1980: systematic analysis of health examination surveys

1106 and epidemiological studies with 370 country-years and $2 \cdot 7$ million participants. Lancet

1107 (London, England) 378:31-40. DOI: 10.1016/S0140-6736(11)60679-X.

1108 D’Antuono A., Dall'Orto VC., Balbo AL., Sobral S., Rezzano I. 2001. Determination of

1109 Bisphenol A in Food-Simulating Liquids Using LCED with a Chemically Modified 
$1110 \quad$ Electrode. Journal of Agricultural and Food Chemistry 49:1098-1101. DOI:

1111 10.1021/jf000660n.

1112 DeBenedictis B., Guan H., Yang K. 2016. Prenatal Exposure to Bisphenol A Disrupts Mouse

1113 Fetal Liver Maturation in a Sex-Specific Manner. Journal of Cellular Biochemistry

1114 117:344-350. DOI: $10.1002 / \mathrm{jcb} .25276$.

1115 Delile H., Blichert-Toft J., Goiran J-P., Keay S., Albarède F. 2014. Lead in ancient Rome's city 1116 waters. Proceedings of the National Academy of Sciences of the United States of America 1117 111:6594-6599. DOI: 10.1073/pnas.1400097111.

1118 Dodds EC., Lawson W. 1936. Synthetic Estrogenic Agents without the Phenanthrene Nucleus. $1119 \quad$ Nature 137:996. DOI: 10.1038/137996a0.

1120 Dodds EC., Lawson W. 1938. Molecular Structure in Relation to Oestrogenic Activity.

1121 Compounds without a Phenanthrene Nucleus. Proceedings of the Royal Society of

1122 London. Series B, Biological Sciences 125:222-232.

1123 Ehrlich S., Calafat AM., Humblet O., Smith T., Hauser R. 2014. Handling of Thermal Receipts

1124 as a Source of Exposure to Bisphenol A. JAMA 311:859-860. DOI:

$1125 \quad 10.1001 /$ jama.2013.283735.

1126 Engelbertsen D., Lichtman AH. Innate lymphoid cells in atherosclerosis. European Journal of

1127 Pharmacology. DOI: 10.1016/j.ejphar.2017.04.030.

1128 Factor A., Ligon WV., May RJ. 1987. The role of oxygen in the photoaging of bisphenol A

1129 polycarbonate. 2. GC/GC/high-resolution MS analysis of Florida-weathered

1130 polycarbonate. Macromolecules 20:2461-2468. DOI: 10.1021/ma00176a023. 
1131 Filardo EJ., Thomas P. 2012. Minireview: G protein-coupled estrogen receptor-1, GPER-1: its

1132 mechanism of action and role in female reproductive cancer, renal and vascular

1133 physiology. Endocrinology 153:2953-2962. DOI: 10.1210/en.2012-1061.

1134 García-Arevalo M., Alonso-Magdalena P., Santos JRD., Quesada I., Carneiro EM., Nadal A.

1135 2014. Exposure to Bisphenol-A during Pregnancy Partially Mimics the Effects of a High-

1136 Fat Diet Altering Glucose Homeostasis and Gene Expression in Adult Male Mice. PLOS

1137 ONE 9:e100214. DOI: 10.1371/journal.pone.0100214.

1138 García-Arévalo M., Alonso-Magdalena P., Servitja J-M., Boronat-Belda T., Merino B., Villar-

1139 Pazos S., Medina-Gómez G., Novials A., Quesada I., Nadal A. 2016. Maternal Exposure

1140 to Bisphenol-A During Pregnancy Increases Pancreatic $\beta$-Cell Growth During Early Life

1141 in Male Mice Offspring. Endocrinology 157:4158-4171. DOI: 10.1210/en.2016-1390.

1142 Gioka C., Eliades T., Zinelis S., Pratsinis H., Athanasiou AE., Eliades G., Kletsas D. 2009.

1143 Characterization and in vitro estrogenicity of orthodontic adhesive particulates produced

1144 by simulated debonding. Dental Materials: Official Publication of the Academy of Dental

1145 Materials 25:376-382. DOI: 10.1016/j.dental.2008.08.010.

1146 Godsland IF., Crook D., Simpson R., Proudler T., Felton C., Lees B., Anyaoku V., Devenport

1147 M., Wynn V. 1990. The Effects of Different Formulations of Oral Contraceptive Agents

1148 on Lipid and Carbohydrate Metabolism. New England Journal of Medicine 323:1375-

1149 1381. DOI: 10.1056/NEJM199011153232003.

1150 Godsland IF., Walton C., Felton C., Proudler A., Patel A., Wynn V. 1992. Insulin resistance,

1151 secretion, and metabolism in users of oral contraceptives. The Journal of Clinical

1152 Endocrinology \& Metabolism 74:64-70. DOI: 10.1210/jcem.74.1.1530790. 
1153 Gorres BK., Bomhoff GL., Morris JK., Geiger PC. 2011. In vivo stimulation of oestrogen

1154

1155

1156

1157

1158

1159

1160

1161

1162

1163

1164

1165

1166

1167

1168

1169

1170

1171

1172

1173

1174

receptor $\alpha$ increases insulin-stimulated skeletal muscle glucose uptake. The Journal of Physiology 589:2041-2054. DOI: 10.1113/jphysiol.2010.199018.

Harder T., Aerts L., Franke K., Van Bree R., Van Assche FA., Plagemann A. 2001. Pancreatic islet transplantation in diabetic pregnant rats prevents acquired malformation of the ventromedial hypothalamic nucleus in their offspring. Neuroscience Letters 299:85-88.

Heine PA., Taylor JA., Iwamoto GA., Lubahn DB., Cooke PS. 2000. Increased adipose tissue in male and female estrogen receptor-alpha knockout mice. Proceedings of the National Academy of Sciences of the United States of America 97:12729-12734. DOI: 10.1073/pnas.97.23.12729.

Huang YQ., Wong CKC., Zheng JS., Bouwman H., Barra R., Wahlström B., Neretin L., Wong MH. 2012. Bisphenol A (BPA) in China: a review of sources, environmental levels, and potential human health impacts. Environment International 42:91-99. DOI: 10.1016/j.envint.2011.04.010.

Ikezuki Y., Tsutsumi O., Takai Y., Kamei Y., Taketani Y. 2002. Determination of bisphenol A concentrations in human biological fluids reveals significant early prenatal exposure. Human Reproduction (Oxford, England) 17:2839-2841.

Inada A., Fujii NL., Inada O., Higaki Y., Furuichi Y., Nabeshima Y. 2016. Effects of 17ßEstradiol and Androgen on Glucose Metabolism in Skeletal Muscle. Endocrinology 157:4691-4705. DOI: 10.1210/en.2016-1261.

Jiang Y., Xia W., Zhu Y., Li X., Wang D., Liu J., Chang H., Li G., Xu B., Chen X., Li Y., Xu S. 2014. Mitochondrial dysfunction in early life resulted from perinatal bisphenol A 
exposure contributes to hepatic steatosis in rat offspring. Toxicology Letters 228:85-92. DOI: 10.1016/j.toxlet.2014.04.013.

1177 Jones BK., Levorse J., Tilghman SM. 2001. Deletion of a nuclease-sensitive region between the

1178 Igf2 and H19 genes leads to Igf2 misregulation and increased adiposity. Human $1179 \quad$ Molecular Genetics 10:807-814.

1180 Joskow R., Barr DB., Barr JR., Calafat AM., Needham LL., Rubin C. 2006. Exposure to 1181 bisphenol A from bis-glycidyl dimethacrylate-based dental sealants. The Journal of the 1182 American Dental Association 137:353-362. DOI: 10.14219/jada.archive.2006.0185.

1183 Judy BM., Welshons WV. 2010. Cellular Localization of Receptors Mediating the Actions of 1184 Steroid Hormones. In: Comprehensive Physiology. John Wiley \& Sons, Inc.,. DOI: $1185 \quad$ 10.1002/cphy.cp070117.

1186 Kim H-S., Nagalla SR., Oh Y., Wilson E., Roberts CT., Rosenfeld RG. 1997. Identification of a 1187 Family of Low-Affinity Insulin-Like Growth Factor Binding Proteins (IGFBPs):

1188 Characterization of Connective Tissue Growth Factor as a Member of the IGFBP

1189 Superfamily. Proceedings of the National Academy of Sciences of the United States of $1190 \quad$ America 94:12981-12986.

1191 Kim K., Park H. 2013. Association between urinary concentrations of bisphenol A and type 2 diabetes in Korean adults: A population-based cross-sectional study. International Journal of Hygiene and Environmental Health 216:467-471. DOI: 10.1016/j.ijheh.2012.07.007.

1195 Kim JB., Pjanic M., Nguyen T., Miller CL., Iyer D., Liu B., Wang T., Sazonova O., Carcamo1196 Orive I., Matic LP., Maegdefessel L., Hedin U., Quertermous T. 2017. TCF21 and the 1197 environmental sensor aryl-hydrocarbon receptor cooperate to activate a pro-inflammatory 
gene expression program in coronary artery smooth muscle cells. PLoS genetics

1199 13:e1006750. DOI: 10.1371/journal.pgen.1006750.

1200 Kow L-M., Pfaff DW. 2016. Rapid estrogen actions on ion channels: A survey in search for mechanisms. Steroids 111:46-53. DOI: 10.1016/j.steroids.2016.02.018.

1202 Kuruto-Niwa R., Tateoka Y., Usuki Y., Nozawa R. 2007. Measurement of bisphenol A concentrations in human colostrum. Chemosphere 66:1160-1164. DOI: 10.1016/j.chemosphere.2006.06.073.

Lang IA., Galloway TS., Scarlett A., Henley WE., Depledge M., Wallace RB., Melzer D. 2008. Association of Urinary Bisphenol A Concentration With Medical Disorders and Laboratory Abnormalities in Adults. JAMA 300:1303-1310. DOI:

Li L., Andersen ME., Heber S., Zhang Q. 2007. Non-monotonic dose-response relationship in steroid hormone receptor-mediated gene expression. Journal of Molecular Endocrinology 38:569-585. DOI: 10.1677/JME-07-0003.

1215 Liao C., Kannan K. 2013. Concentrations and profiles of bisphenol A and other bisphenol analogues in foodstuffs from the United States and their implications for human exposure. Journal of Agricultural and Food Chemistry 61:4655-4662. DOI: 10.1021/jf400445n.

1219 Liao C., Liu F., Guo Y., Moon H-B., Nakata H., Wu Q., Kannan K. 2012. Occurrence of eight bisphenol analogues in indoor dust from the United States and several Asian countries: 
1221 implications for human exposure. Environmental Science \& Technology 46:9138-9145.

1222 DOI: $10.1021 / \mathrm{es} 302004 \mathrm{w}$.

1223 Lin S., Ji W. 2016. Association between insulin resistance and estrogen in sexual precocity of

1224 obese children. Experimental and Therapeutic Medicine 12:2497-2500. DOI:

$1225 \quad 10.3892 /$ etm.2016.3663.

1226 Liu Z., Wolff MS., Moline J. 2005. Analysis of environmental biomarkers in urine using an

1227 electrochemical detector. Journal of Chromatography B 819:155-159. DOI:

$1228 \quad$ 10.1016/j.jchromb.2005.02.005.

1229 Liu J., Yu P., Qian W., Li Y., Zhao J., Huan F., Wang J., Xiao H. 2013. Perinatal bisphenol A

1230 exposure and adult glucose homeostasis: identifying critical windows of exposure. PloS

1231 One 8:e64143. DOI: 10.1371/journal.pone.0064143.

1232 Lopez LM., Grimes DA., Schulz KF. 2012. Steroidal contraceptives: effect on carbohydrate

1233 metabolism in women without diabetes mellitus. The Cochrane Database of Systematic

1234 Reviews:CD006133. DOI: 10.1002/14651858.CD006133.pub4.

1235 Lopez LM., Grimes DA., Schulz KF. 2014. Steroidal contraceptives: effect on carbohydrate

1236 metabolism in women without diabetes mellitus. In: Cochrane Database of Systematic

1237 Reviews. John Wiley \& Sons, Ltd,. DOI: 10.1002/14651858.CD006133.pub5.

1238 López-Cervantes J., Paseiro-Losada P. 2003. Determination of bisphenol A in, and its migration

1239 from, PVC stretch film used for food packaging. Food Additives and Contaminants

20:596-606. DOI: $10.1080 / 0265203031000109495$.

1241 Lopez-Espinosa M-J., Granada A., Araque P., Molina-Molina J-M., Puertollano M-C., Rivas A.,

1242 Fernández M., Cerrillo I., Olea-Serrano M-F., López C., Olea N. 2007. Oestrogenicity of 
paper and cardboard extracts used as food containers. Food Additives and Contaminants 24:95-102. DOI: 10.1080/02652030600936375.

1245 Ma Y., Xia W., Wang DQ., Wan YJ., Xu B., Chen X., Li YY., Xu SQ. 2013. Hepatic DNA methylation modifications in early development of rats resulting from perinatal BPA

Mack LR., Tomich PG. 2017. Gestational Diabetes: Diagnosis, Classification, and Clinical Care. Obstetrics and Gynecology Clinics of North America 44:207-217. DOI: 10.1016/j.ogc.2017.02.002.

Mårtensson UEA., Salehi SA., Windahl S., Gomez MF., Swärd K., Daszkiewicz-Nilsson J., Wendt A., Andersson N., Hellstrand P., Grände P-O., Owman C., Rosen CJ., Adamo

Martin F., Sanchez-Andres JV., Soria B. 1995. Slow [Ca2+]i oscillations induced by

Matsumoto A., Kunugita N., Kitagawa K., Isse T., Oyama T., Foureman GL., Morita M., Kawamoto T. 2003. Bisphenol A levels in human urine. Environmental Health Perspectives 111:101-104.

Melzer D., Rice NE., Lewis C., Henley WE., Galloway TS. 2010. Association of Urinary Bisphenol A Concentration with Heart Disease: Evidence from NHANES 2003/06. PLOS ONE 5:e8673. DOI: 10.1371/journal.pone.0008673. 
1266 Merchant Research \& Consulting Ltd 2017.Bisphenol A (BPA): 2017 World Market Outlook

1267 and Forecast up to 2021. Available at

1268 https://marketpublishers.com/report/industry/chemicals_petrochemicals/bisphenol_a_wo

1269 rld_market_outlook_n_forecast.html (accessed June 23, 2017).

1270 Mountfort KA., Kelly J., Jickells SM., Castle L. 1997. Investigations into the potential

1271 degradation of polycarbonate baby bottles during sterilization with consequent release of

1272 bisphenol A. Food Additives and Contaminants 14:737-740. DOI:

$1273 \quad 10.1080 / 02652039709374584$.

1274 Nadal A., Alonso-Magdalena P., Soriano S., Quesada I., Ropero AB. 2009a. The pancreatic beta-

1275 cell as a target of estrogens and xenoestrogens: Implications for blood glucose

1276 homeostasis and diabetes. Molecular and Cellular Endocrinology 304:63-68. DOI:

$1277 \quad$ 10.1016/j.mce.2009.02.016.

1278 Nadal A., Alonso-Magdalena P., Soriano S., Ropero AB., Quesada I. 2009b. The role of 1279 oestrogens in the adaptation of islets to insulin resistance. The Journal of Physiology

$1280 \quad$ 587:5031-5037. DOI: 10.1113/jphysiol.2009.177188.

1281 Nadal A., Fuentes E., Ripoll C., Villar-Pazos S., Castellano-Muñoz M., Soriano S., Martinez-

1282 Pinna J., Quesada I., Alonso-Magdalena P. 2017. Extranuclear-initiated estrogenic

1283 actions of endocrine disrupting chemicals: Is there toxicology beyond paracelsus? The

1284 Journal of Steroid Biochemistry and Molecular Biology. DOI:

$1285 \quad$ 10.1016/j.jsbmb.2017.01.014.

1286 Nadal A., Ropero AB., Laribi O., Maillet M., Fuentes E., Soria B. 2000. Nongenomic actions of

1287 estrogens and xenoestrogens by binding at a plasma membrane receptor unrelated to 
estrogen receptor $\alpha$ and estrogen receptor $\beta$. Proceedings of the National Academy of Sciences of the United States of America 97:11603-11608.

1290 Nadal A., Rovira JM., Laribi O., Leon-quinto T., Andreu E., Ripoll C., Soria B. 1998. Rapid

1291 insulinotropic effect of 17 beta-estradiol via a plasma membrane receptor. FASEB journal: official publication of the Federation of American Societies for Experimental Biology 12:1341-1348.

Ning G., Bi Y., Wang T., Xu M., Xu Y., Huang Y., Li M., Li X., Wang W., Chen Y., Wu Y., Hou J., Song A., Liu Y., Lai S. 2011. Relationship of Urinary Bisphenol A Concentration to Risk for Prevalent Type 2 Diabetes in Chinese Adults: A Cross-sectional Analysis. Annals of Internal Medicine 155:368. DOI: 10.7326/0003-4819-155-6-20110920000005.

Nohynek GJ., Borgert CJ., Dietrich D., Rozman KK. 2013. Endocrine disruption: Fact or urban legend? Toxicology Letters 223:295-305. DOI: 10.1016/j.toxlet.2013.10.022.

Okada H., Tokunaga T., Liu X., Takayanagi S., Matsushima A., Shimohigashi Y. 2008. Direct Evidence Revealing Structural Elements Essential for the High Binding Ability of Bisphenol A to Human Estrogen-Related Receptor- $\gamma$. Environmental Health Perspectives

Pence HE., Williams A. 2010. ChemSpider: An Online Chemical Information Resource. Journal of Chemical Education 87:1123-1124. DOI: 10.1021/ed100697w.

1307 Pjanic M., Miller CL., Wirka R., Kim JB., DiRenzo DM., Quertermous T. 2016. Genetics and 1308 Genomics of Coronary Artery Disease. Current Cardiology Reports 18:102. DOI: 10.1007/s11886-016-0777-y. 
1310 Polderman KH., Gooren LJ., Asscheman H., Bakker A., Heine RJ. 1994. Induction of insulin

1311 resistance by androgens and estrogens. The Journal of Clinical Endocrinology \&

1312 Metabolism 79:265-271. DOI: 10.1210/jcem.79.1.8027240.

1313 Quesada I., Fuentes E., Viso-León MC., Soria B., Ripoll C., Nadal A. 2002. Low doses of the

1314 endocrine disruptor bisphenol-A and the native hormone $17 \beta$-estradiol rapidly activate

1315 transcription factor CREB. The FASEB Journal 16:1671-1673. DOI: 10.1096/fj.02-

$1316 \quad$ 0313fje.

1317 Ratner RE., Christophi CA., Metzger BE., Dabelea D., Bennett PH., Pi-Sunyer X., Fowler S.,

1318 Kahn SE., Diabetes Prevention Program Research Group 2008. Prevention of diabetes in

1319 women with a history of gestational diabetes: effects of metformin and lifestyle

1320 interventions. The Journal of Clinical Endocrinology and Metabolism 93:4774-4779.

1321 DOI: $10.1210 /$ jc.2008-0772.

1322 Razandi M., Pedram A., Greene GL., Levin ER. 1999. Cell membrane and nuclear estrogen

1323 receptors (ERs) originate from a single transcript: studies of ERalpha and ERbeta

1324 expressed in Chinese hamster ovary cells. Molecular Endocrinology (Baltimore, Md.)

1325 13:307-319. DOI: 10.1210/mend.13.2.0239.

1326 Repossi A., Farabegoli F., Gazzotti T., Zironi E., Pagliuca G. 2016. Bisphenol A in Edible Part

1327 of Seafood. Italian Journal of Food Safety 5. DOI: 10.4081/ijfs.2016.5666.

1328 Rivaton A., Sallet D., Lemaire J. 1983. The photochemistry of bisphenol-A polycarbonate

1329 reconsidered. Polymer Photochemistry 3:463-481. DOI: 10.1016/0144-2880(83)90102-1.

1330 Routledge EJ., White R., Parker MG., Sumpter JP. 2000. Differential Effects of Xenoestrogens

1331 on Coactivator Recruitment by Estrogen Receptor (ER) $\alpha$ and ER $\beta$. Journal of Biological

1332 Chemistry 275:35986-35993. DOI: 10.1074/jbc.M006777200. 
1333 Ruan W., Lai M. 2010. Insulin-like growth factor binding protein: a possible marker for the 1334 metabolic syndrome? Acta Diabetologica 47:5-14. DOI: 10.1007/s00592-009-0142-3.

1335 Rubin BS. 2011. Bisphenol A: An endocrine disruptor with widespread exposure and multiple 1336 effects. The Journal of Steroid Biochemistry and Molecular Biology 127:27-34. DOI: $1337 \quad$ 10.1016/j.jsbmb.2011.05.002.

1338 Sabanayagam C., Teppala S., Shankar A. 2013. Relationship between urinary bisphenol A levels 1339 and prediabetes among subjects free of diabetes. Acta Diabetologica 50:625-631. DOI: 10.1007/s00592-013-0472-z.

1341 Safe SH., Pallaroni L., Yoon K., Gaido K., Ross S., McDonnell D. 2002. Problems for risk assessment of endocrine-active estrogenic compounds. Environmental Health Perspectives 110 Suppl 6:925-929.

1344 Sajiki J., Yonekubo J. 2004. Leaching of bisphenol A (BPA) from polycarbonate plastic to water containing amino acids and its degradation by radical oxygen species. Chemosphere 55:861-867. DOI: 10.1016/j.chemosphere.2003.11.065.

1347 Satoh N., Ogawa Y., Katsuura G., Tsuji T., Masuzaki H., Hiraoka J., Okazaki T., Tamaki M., 1348 Hayase M., Yoshimasa Y., Nishi S., Hosoda K., Nakao K. 1997. Pathophysiological Endocrinology 138:947-954. DOI: 10.1210/endo.138.3.4989.

1352 Schönfelder G., Wittfoht W., Hopp H., Talsness CE., Paul M., Chahoud I. 2002. Parent 1353 bisphenol A accumulation in the human maternal-fetal-placental unit. Environmental Health Perspectives 110:A703-A707. 
1355 Sevak Publications 2008.Polycarbonate A Techno Commercial Profile Part 1 - Technische

1356 Informationsbibliothek (TIB). Available at

1357 https://www.tib.eu/en/search/id/BLSE\%3ARN238100158/Polycarbonate-A-Techno-

1358 Commercial-Profile-Part/?tx_tibsearch_search $\% 5$ Bsearchspace $\% 5 D=$ tn (accessed June

$135922,2017)$.

1360 Shankar A., Teppala S. 2011. Relationship between Urinary Bisphenol A Levels and Diabetes

1361 Mellitus. The Journal of Clinical Endocrinology and Metabolism 96:3822-3826. DOI:

$1362 \quad 10.1210 /$ jc.2011-1682.

1363 Sharma G., Prossnitz ER. 2011. Mechanisms of Estradiol-Induced Insulin Secretion by the G

1364 Protein-Coupled Estrogen Receptor GPR30/GPER in Pancreatic $\beta$-Cells. Endocrinology

1365 152:3030-3039. DOI: 10.1210/en.2011-0091.

1366 Silver MK., O’Neill MS., Sowers MR., Park SK. 2011. Urinary Bisphenol A and Type-2

1367 Diabetes in U.S. Adults: Data from NHANES 2003-2008. PLOS ONE 6:e26868. DOI:

$1368 \quad$ 10.1371/journal.pone.0026868.

1369 Song K-H., Lee K., Choi H-S. 2002. Endocrine disrupter bisphenol a induces orphan nuclear

1370 receptor Nur77 gene expression and steroidogenesis in mouse testicular Leydig cells.

1371 Endocrinology 143:2208-2215. DOI: 10.1210/endo.143.6.8847.

1372 Sowlat MH., Lotfi S., Yunesian M., Ahmadkhaniha R., Rastkari N. 2016. The association

1373 between bisphenol A exposure and type-2 diabetes: a world systematic review.

1374 Environmental Science and Pollution Research 23:21125-21140. DOI: 10.1007/s11356-

$1375 \quad 016-7525-0$. 
1376 Stubbins RE., Najjar K., Holcomb VB., Hong J., Núñez NP. 2012. Estrogen alters adipocyte biology and protects female mice from adipocyte inflammation and insulin resistance. Diabetes, obesity \& metabolism 14:58-66. DOI: 10.1111/j.1463-1326.2011.01488.x.

Susiarjo M., Sasson I., Mesaros C., Bartolomei MS. 2013. Bisphenol a exposure disrupts genomic imprinting in the mouse. PLoS genetics 9:e1003401. DOI: 10.1371/journal.pgen.1003401.

1382 Susiarjo M., Xin F., Bansal A., Stefaniak M., Li C., Simmons RA., Bartolomei MS. 2015. Bisphenol A Exposure Disrupts Metabolic Health Across Multiple Generations in the Mouse. Endocrinology 156:2049-2058. DOI: 10.1210/en.2014-2027.

Takayanagi S., Tokunaga T., Liu X., Okada H., Matsushima A., Shimohigashi Y. 2006. gamma (ERRgamma) with high constitutive activity. Toxicology Letters 167:95-105.

Takeuchi T., Tsutsumi O., Nakamura N., Ikezuki Y., Takai Y., Yano T., Taketani Y. 2004. Gender difference in serum bisphenol A levels may be caused by liver UDPglucuronosyltransferase activity in rats. Biochemical and Biophysical Research Communications 325:549-554. DOI: 10.1016/j.bbrc.2004.10.073.

Talsness CE., Andrade AJM., Kuriyama SN., Taylor JA., vom Saal FS. 2009. Components of plastic: experimental studies in animals and relevance for human health. Philosophical Transactions of the Royal Society of London. Series B, Biological Sciences 364:20792096. DOI: $10.1098 /$ rstb.2008.0281. 
1397 Thomas P., Pang Y., Filardo EJ., Dong J. 2005. Identity of an estrogen membrane receptor 1398 coupled to a G protein in human breast cancer cells. Endocrinology 146:624-632. DOI:

$1399 \quad 10.1210 /$ en.2004-1064.

1400 Tiano JP., Delghingaro-Augusto V., Le May C., Liu S., Kaw MK., Khuder SS., Latour MG., 1401 Bhatt SA., Korach KS., Najjar SM., Prentki M., Mauvais-Jarvis F. 2011. Estrogen 1402 receptor activation reduces lipid synthesis in pancreatic islets and prevents $\beta$ cell failure 1403 in rodent models of type 2 diabetes. The Journal of Clinical Investigation 121:33311404 3342. DOI: $10.1172 / J C I 44564$.

1405 Todaka E., Mori C. 2002. Necessity to establish new risk assessment and risk communication for 1406 human fetal exposure to multiple endocrine disruptors in Japan. Congenital Anomalies 1407 42:87-93. DOI: $10.1111 / \mathrm{j} .1741-4520.2002 . t b 00857 . x$.

1408 Vafeiadi M., Roumeliotaki T., Myridakis A., Chalkiadaki G., Fthenou E., Dermitzaki E., 1409 Karachaliou M., Sarri K., Vassilaki M., Stephanou EG., Kogevinas M., Chatzi L. 2016. 1410 Association of early life exposure to bisphenol A with obesity and cardiometabolic traits 1411 in childhood. Environmental Research 146:379-387. DOI: 10.1016/j.envres.2016.01.017.

1412 Vandenberg LN. 2014. Non-monotonic dose responses in studies of endocrine disrupting 1413 chemicals: bisphenol a as a case study. Dose-Response: A Publication of International 1414 Hormesis Society 12:259-276. DOI: 10.2203/dose-response.13-020.Vandenberg.

1415 Vandenberg LN., Hauser R., Marcus M., Olea N., Welshons WV. 2007. Human exposure to 1416 bisphenol A (BPA). Reproductive Toxicology 24:139-177. DOI:

$1417 \quad$ 10.1016/j.reprotox.2007.07.010. 
1418 Vejrazkova D., Vcelak J., Vankova M., Lukasova P., Bradnova O., Halkova T., Kancheva R.,

1419 Bendlova B. 2014. Steroids and insulin resistance in pregnancy. The Journal of Steroid 1420 Biochemistry and Molecular Biology 139:122-129. DOI: 10.1016/j.jsbmb.2012.11.007.

1421 Verbanck M., Canouil M., Leloire A., Dhennin V., Coumoul X., Yengo L., Froguel P., Poulain-

1422 Godefroy O. 2017. Low-dose exposure to bisphenols A, F and S of human primary

1423 adipocyte impacts coding and non-coding RNA profiles. PloS One 12:e0179583. DOI:

$1424 \quad$ 10.1371/journal.pone.0179583.

1425 Walsh DE., Dockery P., Doolan CM. 2005. Estrogen receptor independent rapid non-genomic

1426 effects of environmental estrogens on [Ca2+]i in human breast cancer cells. Molecular

1427 and Cellular Endocrinology 230:23-30. DOI: 10.1016/j.mce.2004.11.006.

1428 Wang T., Li M., Chen B., Xu M., Xu Y., Huang Y., Lu J., Chen Y., Wang W., Li X., Liu Y., Bi

1429 Y., Lai S., Ning G. 2012. Urinary Bisphenol A (BPA) Concentration Associates with

$1430 \quad$ Obesity and Insulin Resistance. The Journal of Clinical Endocrinology \& Metabolism

1431 97:E223-E227. DOI: 10.1210/jc.2011-1989.

1432 Wedekind L., Belkacemi L. 2016. Altered cytokine network in gestational diabetes mellitus

1433 affects maternal insulin and placental-fetal development. Journal of Diabetes and its

1434 Complications 30:1393-1400. DOI: 10.1016/j.jdiacomp.2016.05.011.

1435 Wei J., Lin Y., Li Y., Ying C., Chen J., Song L., Zhou Z., Lv Z., Xia W., Chen X., Xu S. 2011.

1436 Perinatal exposure to bisphenol A at reference dose predisposes offspring to metabolic

1437 syndrome in adult rats on a high-fat diet. Endocrinology 152:3049-3061. DOI:

$1438 \quad 10.1210 /$ en.2011-0045. 
1439 Welshons WV., Nagel SC., Saal V., S F. 2006. Large Effects from Small Exposures. III.

1440 Endocrine Mechanisms Mediating Effects of Bisphenol A at Levels of Human Exposure.

1441 Endocrinology 147:s56-s69. DOI: 10.1210/en.2005-1159.

1442 Wolff MS., Teitelbaum SL., Windham G., Pinney SM., Britton JA., Chelimo C., Godbold J.,

1443 Biro F., Kushi LH., Pfeiffer CM., Calafat AM. 2007. Pilot Study of Urinary Biomarkers

1444 of Phytoestrogens, Phthalates, and Phenols in Girls. Environmental Health Perspectives

1445 115:116-121. DOI: 10.1289/ehp.9488.

1446 Wozniak AL., Bulayeva NN., Watson CS. 2005. Xenoestrogens at picomolar to nanomolar

1447 concentrations trigger membrane estrogen receptor-alpha-mediated Ca2+ fluxes and

1448 prolactin release in GH3/B6 pituitary tumor cells. Environmental Health Perspectives

$1449 \quad 113: 431-439$.

1450 Wynn V., Godsland I., Niththyananthan R., Adams PW., Melrose J., Oakley NW., Seed M.

1451 1979. Comparison of effects of different combined oral-contraceptive formulations on

1452 carbohydrate and lipid metabolism. The Lancet 313:1045-1049. DOI: 10.1016/S0140-

$1453 \quad 6736(79) 92949-0$.

1454 Yang M., Kim S-Y., Chang S-S., Lee I-S., Kawamoto T. 2006. Urinary concentrations of

1455 bisphenol A in relation to biomarkers of sensitivity and effect and endocrine-related

1456 health effects. Environmental and Molecular Mutagenesis 47:571-578. DOI:

$1457 \quad$ 10.1002/em.20230.

1458 Ye X., Kuklenyik Z., Needham LL., Calafat AM. 2005. Quantification of urinary conjugates of

1459 bisphenol A, 2,5-dichlorophenol, and 2-hydroxy-4-methoxybenzophenone in humans by

1460 online solid phase extraction-high performance liquid chromatography-tandem mass 
spectrometry. Analytical and Bioanalytical Chemistry 383:638-644. DOI: 10.1007/s00216-005-0019-4.

1463 Ye X., Kuklenyik Z., Needham LL., Calafat AM. 2006. Measuring environmental phenols and 1464 chlorinated organic chemicals in breast milk using automated on-line column-switching1465 high performance liquid chromatography-isotope dilution tandem mass spectrometry.

1466 Journal of Chromatography B 831:110-115. DOI: 10.1016/j.jchromb.2005.11.050.

1467 Youn J-Y., Park H-Y., Lee J-W., Jung I-O., Choi K-H., Kim K., Cho K-H. 2002. Evaluation of 1468 the immune response following exposure of mice to bisphenol A: induction of Th1 1469 cytokine and prolactin by BPA exposure in the mouse spleen cells. Archives of $1470 \quad$ Pharmacal Research 25:946-953. 


\section{Figure 1 (on next page)}

The model of BPA effect on insulin resistance and diabetes

Global model of the contribution of endocrine-disrupting chemical BPA to the development of insulin resistance and diabetes in humans. Light and temperature might induce the hydrolysis of polycarbonate plastics and subsequent leaching of BPA into the water and food sources. Once in human tissues BPA exerts its effects through ER receptors alpha, beta and gamma and estrogen mediated gene expression. In addition to the nuclear receptors, BPA can exert its effects through non-genomic, membrane associated receptors. Model indicates that BPA induced endocrine disruption may partially contribute to the development of insulin resistance, with major contributors being modern human diet and genomic composition. ER estrogen receptor. ERR - estrogen-related receptor. GPER - G-protein-coupled estrogen receptor. 


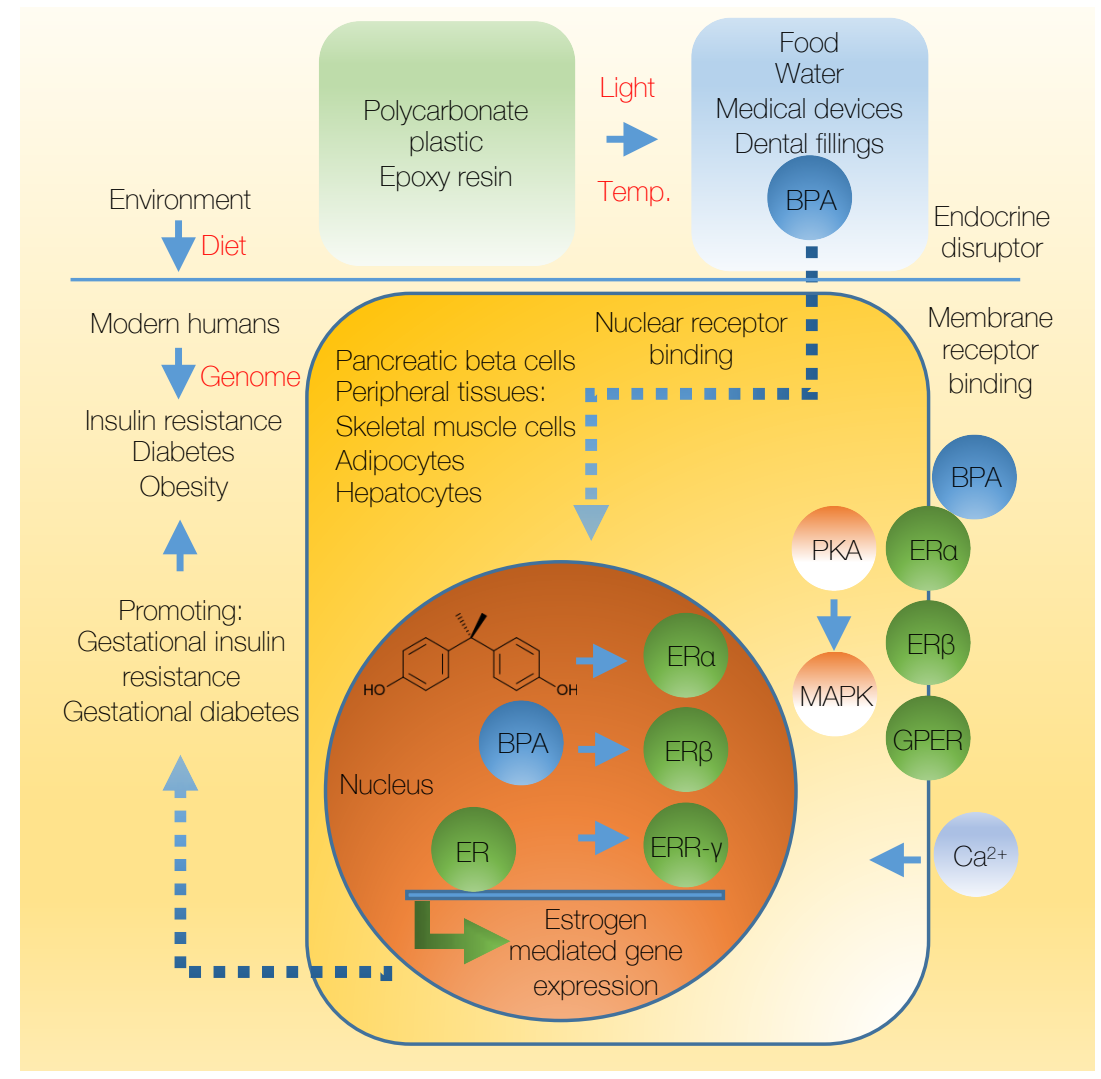




\section{Figure 2 (on next page)}

The prediction of non-monotonic dose response to BPA

BPA may induce non-monotonic dose response as manifested by the appearance of the inverted U-shape curve, e.g. when insulin content is measured in isolated pancreatic islets after treatment with increasing concentrations of BPA (0.1-1000 nM) for 48 hours (AlonsoMagdalena et al, 2008). Computational modeling that takes into account the dimerization kinetics of the estrogen receptors and binding to either endogenous or exogenous ligand, or both (heterodimerization) accurately predicts the appearance of non-monotonic dose responses (both the U-shape and inverted U-shape curves). U-shaped dose response appears in case of the heterodimer $L_{e n} E R-E R L_{e x}$ (also named LXXR) acting as a pure or partial activator, regardless of the nature of exogenous ligand. Non-monotonic inverted U-shape curve appears when exogenous ligand is an agonist, regardless of the activity of the heterodimer. Finally, monotonic response can also arise in two cases. $L_{e n}$ - endogenous ligand, $\mathrm{L}_{\mathrm{ex}}$ - exogenous ligand. 


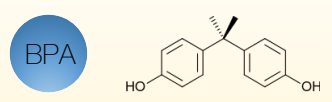

Non-monotonic dose response

U shape curve

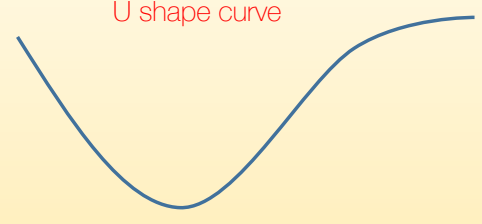

Heterodimer pure/partial activator $+$

Exogenous ligand as agonist Exogenous ligand as antagonist

Non-monotonic dose response Inverted U shape curve

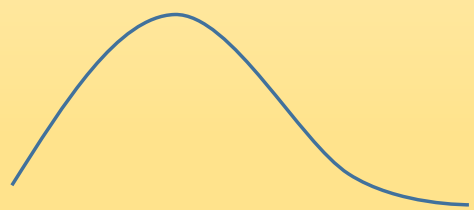

Heterodimer pure/partial activator Heterodimer absent Heterodimer repressor $+$

Exogenous ligand as agonist
Homodimerization

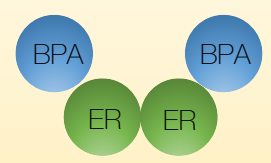

Heterodimerization

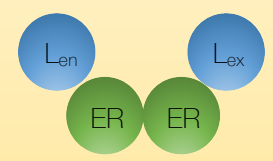

Monotonic dose response

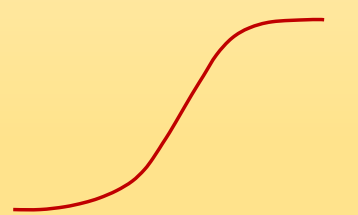

Heterodimer absent Heterodimer repressor $+$

Exogenous ligand as antagonist 
Figure 3 (on next page)

Effective transmission of BPA effects to male offspring in mice

Acute BPA treatment during gestation leads to severe glucose intolerance, decreased insulin production, and altered glucose metabolism that is being transferred to the male offspring. During the early life in male offspring there is a surplus in insulin signaling and insulin production that ultimately leads to decreased pancreatic beta mass and glucose intolerance in adulthood. Female offspring is protected from the BPA effects due to the higher levels of the enzyme involved in BPA glucuronidation process and elimination of BPA from the organism. 


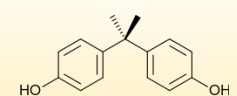

Treatment with BPA of pregnant females

\section{BPA}

FO

1 Acute treatment

V $10 \mu \mathrm{g} / \mathrm{kg}$ on days 9-16 of gestation

\section{Parental generation}

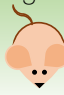

Severe glucose intolerance Decreased insulin secretion Reduced pancreatic beta-cell mass

Transmission of altered glucose metabolism to offspring

\section{Female offspring}<smiles>[C]1CCCCC1</smiles>

Higher UDP-glucuronosyltransferase liver levels

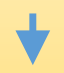

BPA glucuronidation Elimination of BPA from the organism
Male offspring<smiles>CC1CCCCC1C</smiles>

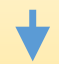

Early life - D0, D21, D30

Surplus of insulin signaling Increased pancreatic beta-cell mass Increased insulin levels
F1

Adulthood - D100

Decreased pancreatic betacell mass

Increased fasting glucose Glucose intolerance Diabetes Obesity 


\section{Figure 4(on next page)}

BPA induced epigenetic modifications are actively transmitted to offspring

BPA can induce changes in DNA methylation in the placental tissue, as well as in the embryo of the F1 generation. Modifications in DNA methylation at the DMR - differentially methylated regions induce changes in gene expression and LOI - loss of imprinting (loss of monoallelic expression) of at least three imprinted genes (Snrpn, Igf2 and Kcnq1ot1). In the case of Igf2 increased methylation leads to the loss of expression of the neighboring $\mathrm{H} 19$ gene from the maternal allele and subsequent biallelic expression of Igf2. In the case of Snrpn and Kcnq1ot1 the loss of methylation at the DMR leads to biallelic expression of these genes. In the liver in F1 and F2 generations, DNA methylation of the Gck (glucokinase) gene promoter decreases its expression. In F1 generation Gck contains hypermethylated one CpG island (out of $5 \mathrm{CpG}$ islands in total present in the promoter of the Gck gene). In F2 generation, DNA methylation is increased as all 5 CpG islands become methylated. 
Parental generation

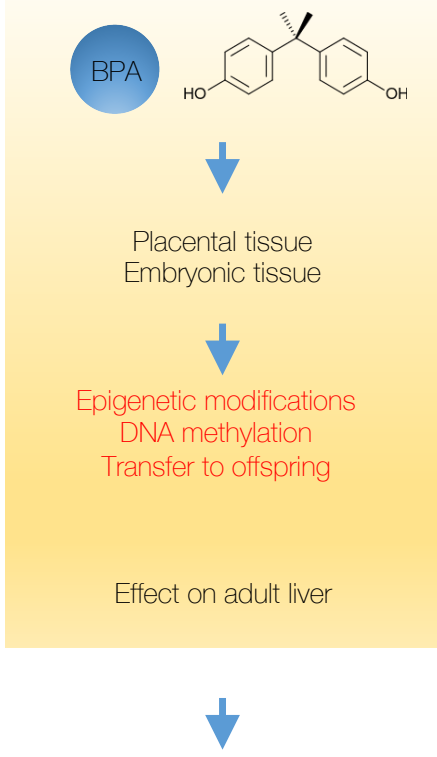

F1 generation

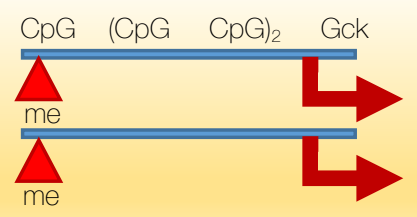

F1 generation

Loss of imprinting - LOI

DMR Snrpn
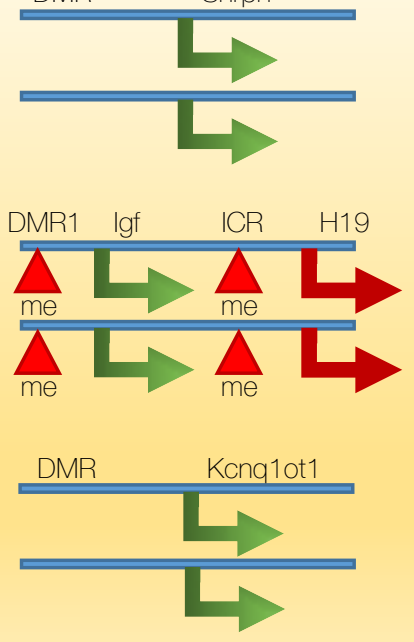

F2 generation

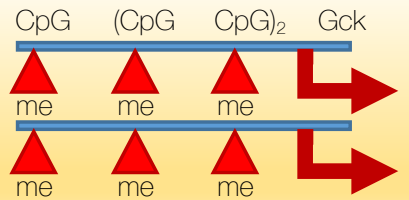


Figure $\mathbf{5}$ (on next page)

Maximal biological effect of BPA is confined to a narrow range and dependent on dose, gender and developmental stage

BPA exerts effects that follow non-monotonic dose response (e.g. the inverted U-shape curve), therefore a narrow concentration window might exist that is essential for the BPA action. Concordantly, BPA will show its maximal effect in the narrow window of developmental stages (e.g. P6-PND0). These confined ranges of maximal BPA effects, together with the gender related differences, comprise a specific set of conditions for the maximal biological and physiological effect of BPA. 


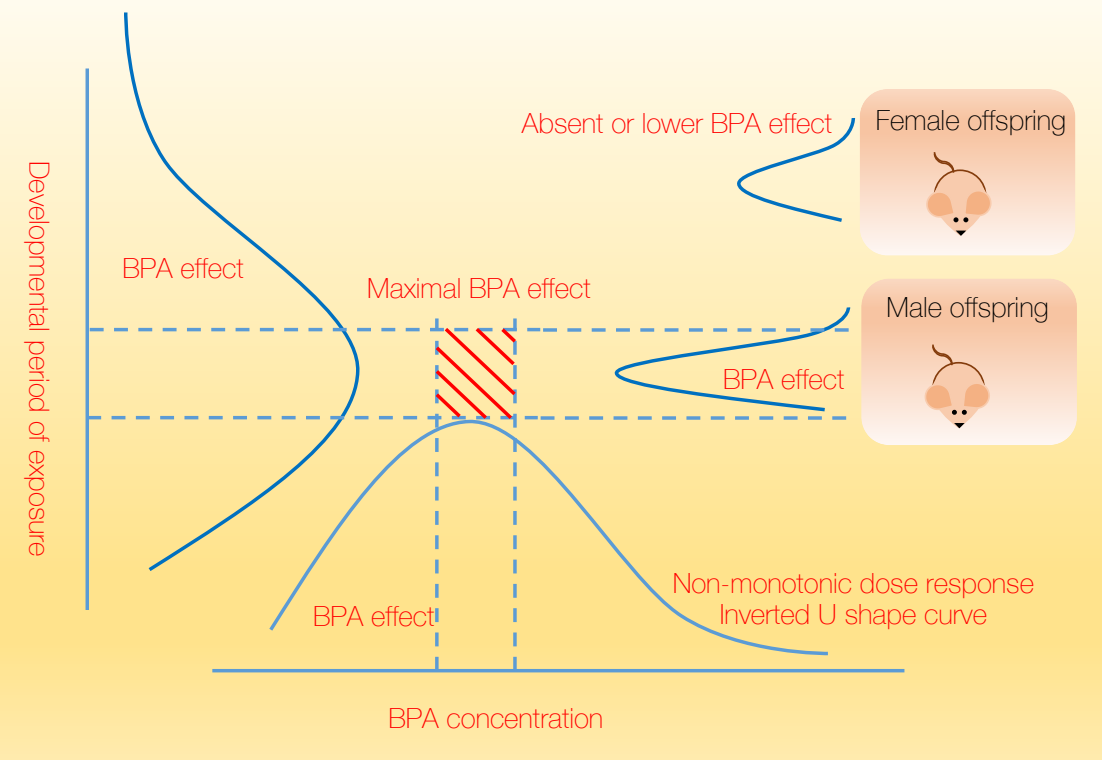

